\title{
LA ORGANIzACIÓN JURÍdICA DEL PODER: EL SISTEMA DE FUENTES EN LA CONSTITUCIÓN BOLIVIANA DEL 2009
}

\author{
JURIDICAL ORGANIZATION OF \\ POWER: SOURCE SYSTEM IN THE \\ CONSTITUTION OF BOLIVIA OF 2009
}

\author{
Horacio Andaluz Vegacenteno* \\ Fecha de recepción: 30 de junio de 2009 \\ Fecha de aceptación: 8 de septiembre de 2009
}

* Abogado, Árbitro (CAINCO), profesor de derecho (UPSA), Máster en Derecho Internacional (Universidad Complutense de Madrid), antiguo alumno de la Academia de La Haya de Derecho Internacional, Master of Laws (Harvard Law School). Últimas publicaciones: Positivismo normativo y derecho internacional. 201 Págs. Plural/CERID. (2005); El derecho de la sucesión de Estados (Revista de Derecho de la Pontificia Universidad Católica de Valparaíso xxvir. $2^{\circ}$ semestre 2006. Revista de Derecho de la Universidad Miguel Hernández de Elche. España. nº 2, 2007; International Law Revista Colombiana de Derecho Internacional. n ${ }^{\circ}$ 9. mayo (2007); Crítica de juridicidad de un cuerpo normativo: el caso de la Ley de reconducción de la Reforma Agraria (con ANTONIO ANDALUz). 63 Págs. ABEC/El País. (2007); El derecho internacional en el sistema de fuentes, propuesta de artículos para la Nueva Constitución de Bolivia. Anuario Mexicano de Derecho Internacional. Volumen VIII. (2008) y Anuario de derecho constitucional latinoamericano (2009); El significado jurídico de la cláusula de sumisión en la jurisprudencia (con Antonio Andaluz) Revista Boliviana de Derecho. $\mathrm{n}^{\circ}$ 6. julio (2008); El control de la constitucionalidad desde la teoría del derecho. Revista de Derecho de la Pontificia Universidad Católica de Valparaíso xxxi. $2^{\circ}$ semestre. (2008); y, La justicia constitucional en el Estado de derecho. Revista General de Derecho Público Comparado. España. no 4. (2009). En preparación: Justicia constitucional, fuentes e interpretación. Miembro de número de la Academia Boliviana de Estudios Constitucionales. Miembro del Consejo Editorial de la Revista Boliviana de Derecho. 


\section{RESUMEN}

La recientemente en vigor Constitución boliviana del 2009 trae consigo cambios en la estructura del sistema jurídico. Este artículo analiza dichas transformaciones a través de las relaciones formales entre las distintas fuentes del derecho y expone la estructura unitaria y a la vez territorialmente descentralizada inaugurada por la Constitución. Además de un marco teórico previo, el artículo está dividido en dos partes principales: la primera se ocupa de la Constitución como fuente del derecho, e incluye las consecuencias jurídicas de su supremacía, los límites de la cláusula de interpretación de la Constitución y el carácter vinculante de los precedentes del Tribunal Constitucional; la segunda parte presenta las fuentes de derecho ordinario, sus respectivas posiciones en la estructura del sistema y las relaciones formales de jerarquía y competencia entre ellas.

Palabras clave: supremacía constitucional, continuidad del sistema jurídico, fuentes del derecho, estructura del sistema jurídico, relaciones formales entre fuentes, jerarquía, competencia, poderes normativos.

Palabras clave descriptor: Bolivia, constitución, fuentes, política y poder judicial, derecho, fuentes.

\section{ABSTRACT}

The recently in force Bolivian Constitution of 2009 brings a change in the structure of the legal system. This paper analyzes such change through the formal relations among the legal sources and exposes the structure of the Unitarian and territorially decentralized State shaped by the Constitution. Besides a previous theoretical frame, the paper is divided into two main parts: the first one regards the Constitution as a legal source, and includes the legal consequences of its supremacy, the limits of the interpretation clause of the Constitution and the application of the stare decisis doctrine to the Constitutional Court precedents; the second part exposes the ordinary legal sources, its respective position in the structure of the legal system and the formal relations among them.

Key words: constitutional supremacy, continuity of the legal system, sources of law, structure of the legal system, formal relations among sources of law, hierarchy, jurisdiction, normative powers.

Key words plus: Bolivia, Constitution, Sources, Justice and politics, Law, Sources. 


\section{LAS FUENTES DEL DERECHO Y LA ESTRUCTURA DEL SISTEMA JURÍDICO}

En el pensamiento jurídico el conocimiento formal del sistema antecede a su conocimiento material. La determinación del significado jurídico de una norma depende de su posición en la estructura del sistema y de sus relaciones con las demás formas normativas del mismo. De ahí la relevancia de las fuentes en la teoría general del derecho. El estudio de un sistema positivo se hace desde su norma fundacional porque ésta determina las condiciones de validez de las normas que pertenecen a él. En esta medida, la norma fundacional determina también las relaciones entre las formas normativas del sistema. Estas relaciones son las que dan a cada sistema positivo su estructura específica. Por esto, el estudio positivo de las fuentes se hace desde las constituciones que estructuran los sistemas positivos que fundan al condicionar la validez de la pluralidad de normas que se le subordinan. Con esto, lo que el sistema de fuentes hace es organizar jurídicamente el ejercicio del poder.

A través de las fuentes el derecho regula su propia creación. Esto se da al someter la producción de nuevas normas jurídicas al cumplimiento de condiciones de validez determinadas por normas vigentes. De esto el normativismo deriva la unidad del sistema jurídico. Tal unidad resulta de la existencia de normas que determinan los elementos que componen el sistema. Tales normas son las fuentes. Como sirven de método para la identificación de otras normas, las fuentes también son denominadas metanormas, "normas sobre la producción jurídica" o, en términos de HART", "reglas secundarias".

Como categoría analítica, las condiciones de validez se individualizan en 1) normas de competencia formal, que atribuyen a un órgano la competencia para producir derecho (verbigracia, el artículo 158. I. 3 de la Constitución, que atribuye a la Asamblea Legislativa Plurinacional la competencia para dictar leyes); 2) normas de procedimiento, que disciplinan el curso procesal para el ejercicio de la competencia formal (para las leyes, el procedimiento legislativo de los artículos 162 a 164 de la Constitución en cuanto a la producción de leyes ordinarias); 3) normas de competencia material, que determinan la materia en que puede ejercerse la competencia normativa (verbigracia, el artículo 411. II de la Constitución, que atribuye competencia al órgano legislativo para reformar parcialmente la Constitución); y 4) normas de contenido, siempre que sean superiores a las normas producidas por la fuente objeto de análisis (así, las leyes están condicionadas por el contenido de la Constitución y los decretos por el contenido de la Constitución y las leyes).

1 El de HART es el mejor intento orientado a construir una teoría del conocimiento jurídico alrededor del carácter dinámico del derecho, a partir de su diferenciación entre reglas primarias (normas de conducta) y secundarias (normas de competencia). 
Las tres primeras condiciones son criterios de validez de tipo dinámico (formal). Su infracción produce, respectivamente, vicios de competencia formal, de procedimiento y de competencia material. Estos vicios operan sobre las disposiciones jurídicas como formas continentes (cuyo contenido son las normas jurídicas).

La cuarta condición de validez es de tipo estático (material). Su infracción produce un vicio material o sustantivo. Opera sobre las normas jurídicas contenidas, no sobre las formas continentes (disposiciones jurídicas). Habida cuenta que todas las normas son resultado de un proceso de interpretación de las disposiciones que las contienen, el vicio material no significa que sea inválida la disposición que contenga una norma inválida, sino la disposición que no contenga ni una sola norma (ni una sola interpretación posible) válida. Este es el principio de conservación de la norma, que consiste en preferir la construcción interpretativa que conserve la validez de una disposición a la que concluya en su invalidez. En teoría general del derecho este principio es un imperativo de la unidad del sistema. Por esto en derecho constitucional él mismo deriva de interpretar el ordenamiento conforme a la Constitución. La interpretación antinómica de una disposición no viene necesariamente aparejada con su declaratoria de invalidez (no debe confundirse la conservación de la norma con la presunción de su validez). Esto último depende de que el sistema haya conferido al intérprete el poder para emitir tal declaración. Por esto es concebible que en el sistema coexistan interpretaciones antinómicas, en la medida que el poder de interpretar no está siempre acompañado del poder de declarar la invalidez. De ahí que la exigencia de conservar nazca de la unidad del sistema. Al contrario, si ambos poderes estuviesen siempre acompañados, la unidad del sistema no se vería jamás comprometida. Asegurada la unidad, la conservación de la norma también arraiga en la salud del sistema, evitando la generación de vacíos normativos indeseables. Aplicada la conservación de la norma a la validez del derecho ordinario, la declaratoria de inconstitucionalidad no significa que una norma no es conforme con la Constitución, sino que su disconformidad es manifiesta: que va más allá de cualquier duda razonable a favor de su constitucionalidad.

Normativamente, son fuentes los actos autorizados por una norma jurídica del sistema para producir, innovar o derogar el derecho vigente. Esta es una definición formal, deudora de la teoría iniciada por Merk en sus Prolegómenos de una teoría de la construcción escalonada del derecho (1931). KELSEN, cuya teoría del derecho para entonces se encontraba atrapada en una concepción estática del fenómeno jurídico, introdujo a su teoría la concepción dinámica de su "querido alumno", que está presente desde la primera edición de su Teoría pura del derecho (1934).

2 Uno de los primeros discípulos de Kelsen en la Universidad de Viena fue Merkl. Kelsen llegó a 
Las teorías tradicionales definen las fuentes atendiendo o bien al criterio sustantivo o bien al de la eficacia erga omnes. Por el primero, son fuentes las normas generales y abstractas; por el segundo, lo son aquellas cuya oponibilidad es absoluta. Ambos criterios son útiles únicamente para efectos de una exposición de las distintas formas normativas, pero carecen de relevancia jurídico-positiva. Ya que el sistema jurídico no atribuye especificidades propias a las normas por el hecho de su clasificación como fuentes, cualquier diferenciación entre "actos fuente" y "actos no fuente" no comporta consecuencias jurídicas. La teoría formal no hace esta distinción. Para ella todas las normas son fuentes. Que una norma sea fuente de otra significa que la primera es fundamento de validez de la segunda. De esta manera, el acto de producción jurídica tiene existencia positiva. No es externo al sistema jurídico, sino que es el propio sistema jurídico en movimiento ${ }^{3}$ (carácter dinámico).

Dice MERKL que el análisis estructural del fenómeno jurídico puede hacerse según el contenido de las normas o según su fuente de producción (forma). A diferencia de las formas, los contenidos en el derecho son inagotables. En cambio, hay una "economía de la forma", ya que vasta que fuese la multiplicidad de formas, frente a la diversidad de su contenido siempre tendrá un límite cierto. De ahí su fórmula: "la forma es finita, el contenido infinito"4.

En razón de la forma, 1) la relación entre una fuente y otra se expresa en términos de delegación de poder: una fuente sólo tiene poder normativo en la medida en que le haya sido delegado por otra fuente y dentro de los límites de tal delegación. 2) Cada delegación de poder determina las condiciones de validez para la introducción de nuevo derecho al sistema jurídico. 3) Como las normas son creadas por aplicación de otras (aquellas que determinan sus condiciones de validez), las nuevas normas derivan de aquellas que las

considerarlo "cofundador" de la teoría pura del derecho al reconocer el "gran significado de su obra". De hecho, escribió que "el mérito de haber concebido y expuesto el orden jurídico como un sistema genético de normas de derecho que van concretándose gradualmente desde la constitución, pasando por la ley y el decreto y demás fases intermedias, hasta los actos jurídicos individuales de ejecución, corresponde a Adolf MerkL". (cit. por Heinz MAYer. "La teoría de la construcción jurídica escalonada". En Robert Walter. Problemas centrales de la teoría pura del derecho. Pág. 63. $1^{a}$ edición. Bogotá. Universidad Externado de Colombia. (2001).

3 Este es el nervio de la teoría de las fuentes de Kelsen: "Cuando una norma jurídica es válida por haber sido creada en la forma establecida por otra, la última constituye la razón de validez de la primera. (...). La norma que determina la creación de otra es superior a ésta; la creada de acuerdo con tal regulación, inferior a la primera". "(...) cada norma jurídica es fuente del precepto cuya creación regula, al determinar el procedimiento de elaboración y el contenido de la norma que ha de ser creada. En tal sentido, toda norma jurídica superior es fuente de la inferior. (...). La fuente del derecho no es, por tanto, como la expresión parece sugerirlo, una entidad diversa del derecho, dotada de una existencia independiente frente a éste; por sí misma, la fuente es en todo caso derecho: una norma jurídica superior en relación con otra inferior o sea el método de creación de una norma inferior determinado por otra, lo cual constituye un contenido específico del derecho" (Hans Kelsen. Teoría general del derecho y del Estado. Págs. 146, 155-156. $5^{\text {a }}$ reimpresión. México D.F. UNAM. (1995).

4 Cit. por Heinz MaYer, en ob. cit. en nota al pie 2. Pág. 65. 
autorizan. Al estar condicionadas a las normas existentes (normas subordinantes), las nuevas normas les son inferiores (normas subordinadas). Se forma así una "cadena de validez" (RAz) o "de subordinación" (WRIGHT), que da al sistema jurídico una estructura representable jerárquicamente. Esta es una jerarquía lógica que deriva de una concepción de la filosofía del derecho sobre el proceso de producción jurídica. Como se forma a partir de las relaciones de validez entre sus normas, es una estructura ínsita del sistema jurídico. 4) Como consecuencia de (3), todo acto jurídico es a la vez la aplicación de una norma y la creación de otra (se pone fin al dualismo entre creación y aplicación del derecho). Por tanto, 5) se disuelve la distinción conceptual entre "actos fuente" y "actos no fuente": si todos los actos normativos crean derecho, y no sólo lo aplican, todos son fuentes del derecho.

Como filosofía del derecho, la teoría formal es un instrumento para el conocimiento y la explicación del derecho positivo. Nada más. Es, por tanto, un error confundir la teoría con su representación gráfica en forma de pirámide. En consecuencia, es erróneo evaluar la solvencia científica de esta teoría compulsando tal representación esquemática con la estructura positiva de un sistema determinado. Aunque la graficación piramidal depaupera la teoría que pretende representar, no se puede confundir una filosofía del derecho, como instrumento de conocimiento, con el derecho positivo, como objeto de conocimiento 5 . La teoría formal hace visibles los vínculos entre las fuentes; no los produce. Tampoco impone configuración positiva alguna a los sistemas jurídicos, porque la estructura de un sistema jurídico positivo sólo es deducible de sí mismo. En tanto que razonamiento abstracto, la teoría formal da cuenta del proceso de producción normativa a través del cumplimiento de las condiciones de validez. Corresponde a cada intérprete la individualización conceptual e identificación de las específicas condiciones de validez de las formas normativas en su sistema positivo.

Esto lo comprendía el propio MerkL, que acompañó su teoría formal de las fuentes con su tesis de la fuerza jurídica de los actos normativos, distinguiendo la teoría estructural (descripción lógico-filosófica) de la estructura positiva de los sistemas jurídicos (descripción jurídico-positiva). Esta descripción la hizo a partir de las condiciones formales de validez del proceso de producción normativa, aunque la competencia material del órgano productor no fue individualizada como tal.

5 Este punto ha sido tocado por RAz. Por su mayor plástica para graficar las relaciones intranormativas, él reemplaza la pirámide por el diagrama en forma de árbol, que también representa de mejor manera la organización jerárquica del derecho y las relaciones directas e indirectas de validez entre las normas, que era el objetivo principal de KELSEN al usar el modelo piramidal, a la vez que evita las implicaciones indeseables de la pirámide, entre ellas "la más indeseable": "la apariencia de que hay siempre el mismo número de niveles en las pirámides de todo sistema positivo" (cfr. JosEPH RAZ. The concept of a legal system. Pág. 99. 2a edición. Nueva York. Oxford University Press. (1980). 
Según la tesis de la fuerza jurídica, 1) si la producción de todos los actos normativos está condicionada, entonces la dinámica de producción normativa está determinada por la norma jurídica que los condiciona (jerarquía lógica). 2) Si los órganos jurídico-positivos están autorizados a producir determinados actos, ¿tendrán también la correspondiente autorización para su anulación? 3) Para Merke la respuesta depende del "ámbito de vigencia específico de lo jurídico": "lo jurídico vale en tanto que en el ámbito de fenómenos jurídicos condicionantes no sean llenados manifiestamente los presupuestos para la invalidez de los fenómenos jurídicos condicionados" (presunción de validez). 4) Por tanto, la capacidad de modificación de normas jurídicas es un problema de derecho positivo. Cada sistema asigna una posición a las diversas fuentes dentro de la estructura del ordenamiento. Esa posición es la fuerza jurídica: la capacidad de una fuente para incidir en el sistema, ya sea introduciendo nuevas normas o derogando las existentes (jerarquía positiva). Y 5) la fuerza jurídica específica de las diversas formas normativas se determina por el grado de complejidad de sus respectivos procesos de creación. El axioma es mientras más compleja la forma, más importante la fuerza. El grado de complejidad resulta de combinar las normas formales de competencia con las de procedimiento (condiciones de validez 1 y 2). Salvo regla contraria, una forma normativa sólo puede declinar o innovarse siguiendo su mismo proceso de creación ${ }^{7}$. De ahí que la fuente originada en un proceso menos complejo no pueda prevalecer contra las fuentes originadas en procesos de mayor complejidad. De esta manera, la importancia de cada forma normativa es atribuida por el propio derecho positivo, con independencia de las razones materiales de lege ferenda que justificaron su inclusión en el sistema como fuente del derecho. Así, la mayor fuerza jurídica de la ley con respecto al decreto se explica por la mayor complejidad de su proceso de creación (justificación positiva), sin necesidad de invocar su mayor legitimidad democrática (justificación política).

La distinción entre jerarquía lógica y jerarquía positiva no sugiere en absoluto que se den en compartimientos estancos, cual si, disociada la una de la otra, la primera rigiese en el solo plano de la especulación filosófica y la segunda en el derecho vigente. Antes bien, es la teoría formal de la primera la que precisamente explica la estructura vigente en un sistema positivo. Aunque la jerarquía lógica no impone la jerarquía positiva, la positiva sólo puede ser determinada en razón de la lógica, desde que las relaciones de validez que

6 Cit. por Gabriele Kucsko-Stadlmayer. La contribución de Adolf Merkl a la teoría pura del derecho. Pág. 169. En ob. cit. en nota al pie 2.

7 Esto descansa sobre una regla de tan vieja data en el conocimiento jurídico como que ya ULPIANO la había introducido al Digesto: "Nada es tan natural como que cada cosa se la disuelva del mismo modo como se la ligó" (Nihil tam naturale est, quam eo genere quidque disolvere, quo colligatum est": Digesto, libro I, título III, Ley 37), y que condice con el Ejus est tollere, cujus est condere: "Quien tiene poder para hacer una cosa lo tiene para deshacerla". 
hacen a la jerarquía positiva son descritas por la jerarquía lógica. De hecho, los sistemas jurídicos no suelen tener disposiciones positivas expresas que describan sus estructuras normativas, y cualquiera que lo intente a lo sumo llegará a perfilar en términos muy generales la estructura que se forma a partir de las relaciones positivas entre sus normas (es el caso del artículo 410. II de la Constitución, como se verá en su momento). En estos casos, corresponde al intérprete determinar la jerarquía positiva del sistema. Para hacerlo tendrá que recurrir a las relaciones de validez entre las normas (jerarquía lógica).

De esta manera, la estructura positiva de un sistema se determina por el cumplimiento de las condiciones impuestas para la validez de sus distintas formas normativas. En este sentido, un sistema no se estructura sólo en términos de jerarquía, sino también de competencia (salvo un sistema extremadamente simple y primitivo que permita una derivación lineal de las normas).

Son dos, por tanto, los criterios de estructuración: 1) la jerarquía positiva de las distintas formas normativas. De esta manera, los preceptos de mayor fuerza jurídica tienen mayor significación en el sistema que los de menor fuerza. Y 2) la competencia material de los distintos órganos formales de producción (condición de validez 3). En este caso, la estructura del sistema no se determina por la fuerza jurídica, sino por las normas que atribuyen competencia material a los órganos productores (normas de competencia). Estas normas distribuyen la competencia normativa entre fuentes de la misma fuerza, o la reservan a favor de una fuente inferior. Por tanto, la regla es que se sustituye el criterio de jerarquía ahí donde el sistema ha introducido el de competencia material. El hecho de atribuir a una fuente la regulación de una materia conlleva la invalidez de los actos que la invadieran. No viene al caso considerar si el contenido de la norma de fuente incompetente es antinómico con el de la fuente competente. Lo que vicia la validez del acto es el solo hecho de incursionar en campo material ajeno y, por tanto, normar sin competencia ${ }^{8}$.

8 Un ejemplo paradigmático es el de los reglamentos camerales. En este caso, existe una norma de competencia en los artículos 159.1 y 160.1 de la Constitución reservando a las cámaras legislativas la atribución de dictar sus propios reglamentos. De esta manera, aun cuando siendo de fuente superior, un reglamento legislativo promulgado por ley debe ceder ante uno aprobado por resolución cameral. La razón: respecto de esta materia en particular, el sistema está estructurado según la competencia material de los órganos productores, por lo que la ley sería inconstitucional por violar la reserva de competencia hecha por la Constitución. Ni siquiera importa preguntar si la ley es efectivamente antinómica a la resolución cameral, pues lo que la hace inconstitucional es la actuación ultra vires de su órgano productor. En este ejemplo, la jerarquía entre la ley y la resolución cameral no juega papel alguno, sólo importa la de la Constitución. Cuando se trata del criterio de competencia, la única jerarquía relevante es la de la norma que distribuye la competencia entre las fuentes en compulsa: ella tiene que ser superior a ambas fuentes, pues de lo contrario, no puede condicionar la validez de éstas a través de la competencia material de sus respectivos órganos productores. Esto es lo que hace que el vicio de competencia se sustancie como una infracción a la norma jerárquicamente superior responsable de la distribución de materias (norma de competencia). 
De manera que la estructura positiva de un sistema jurídico se configura por la coexistencia de ambos criterios, incluso al mismo nivel jerárquico. Esta estructura resulta de la interpretación de las normas constitucionales sobre la producción jurídica. Al respecto, el propio artículo 410, parágrafo II de la Constitución, atinente a la estructura del sistema, deberá ser objeto de reconstrucción, con el fin de eliminar antinomias entre su descripción literal y la estructura que se configura tomando el íntegro del texto formal de la Constitución.

\section{LA CONSTITUCión COMO FUENTE DEL SISTEMA JURÍDICO}

\section{LA CONTINUIDAD DEL SISTEMA JURÍDICO: LA VALIDEZ DEL DERECHO PRECONSTITUCIONAL Y LA COMPETENCIA FORMAL DE LOS ÓRGANOS PRECONSTITUIDOS}

De la sola entrada en vigor de la norma que define las condiciones de validez del sistema jurídico (la Constitución), no se deduce la invalidez automática del derecho preexistente, lo mismo que tampoco la incompetencia formal de los órganos productores preconstituidos. En teoría general del derecho se dice que los sistemas jurídicos tienen vocación de persistencia, porque mantienen su identidad a pesar de que sus normas varíen. Así, visto como una línea sostenida de tiempo, el sistema jurídico aparece como una realidad de existencia continua, pero examinado en distintas secciones de la línea se revela como una sucesión de subsistemas jurídicos. Tal sucesión es causada por los actos de derogación y de promulgación de normas. De ahí que la derogación de la norma sucedida y la promulgación de la norma sucesora no produzcan una ruptura en la continuidad del sistema, sino una sucesión reglada por el derecho positivo del propio sistema. De esto resulta que el sistema jurídico, por ser tal, ni por materia ni por tiempo puede darse en compartimientos estancos. De manera que con respecto a la anterior Constitución, la del 2009, implica continuidad no ruptura; donde el paso de una norma a otra se rige por la última, por ser el único texto constitucional positivo vigente?

9 Es un hecho incontrovertible que con el cambio de Constitución la continuidad del sistema jurídico boliviano no está en duda, aunque la fuente de validez de sus normas haya cambiado. Revisemos un poco la teoría en la materia. Es cierto que para KELSEN no existe continuidad entre dos constituciones cuando la nueva es hecha en una forma no prevista en la anterior. El caso paradigmático sería el de la revolución victoriosa, que impone un nuevo orden a partir de la fuerza de los hechos. En estos casos, si el derecho prerrevolucionario continúa siendo válido, es porque el nuevo orden le confiere validez, sea expresa o tácitamente, y en eso consiste la ruptura de la continuidad: en la sustitución de la fuente de validez del sistema por procedimientos no previstos, pero no en la extinción del sistema, pues la existencia de los sistemas jurídicos es tan compleja como complejas son las formas sociales que regula. Se necesita mucho más que este tipo de ruptura para extinguirlo. La existencia 
La continuidad es una sola realidad que en la práctica presenta estas dos vertientes: 1) continuidad en el derecho preconstitucional (las fuentes vigentes antes de la publicación de la Constitución actual), y 2) sucesión en las competencias de los órganos constitucionales preconstituidos (lo que incluye sus competencias formales para producir nuevas normas).

Respecto a lo primero, con la abrogación de la Constitución anterior, la fuente de validez del derecho preconstitucional es ahora la Constitución del 2009. Consecuentemente, el derecho que resulte contrario a la Constitución vigente adolecerá de una inconstitucionalidad sobrevenida, pues si bien era constitucional con referencia al contenido de la anterior Constitución, no lo sería con referencia al contenido de la vigente. La regla, por consiguiente, es que la validez del derecho preconstitucional se determina según la Constitución del 2009. Esto implica: 1) que el enjuiciamiento de su constitucionalidad debe hacerse conforme al contenido material del texto vigente; 2) que la declaratoria de inconstitucionalidad debe sujetarse al procedimiento previsto en el texto vigente; y 3) que hasta en tanto tal procedimiento no sea agotado, el derecho preconstitucional continúa siendo válido (presunción de validez).

La existencia de una norma jurídica es un dato formal objetivo, no un juicio de valor sobre sus méritos o deméritos según la apreciación personal de sus destinatarios. Por ello que para toda la producción normativa rija la presunción de que las normas son válidas hasta que el órgano atribuido de competencia por el sistema jurídico no declare su invalidez. De manera que la invalidez de una norma también es un dato objetivo, pues, tanto como constitutivamente el sistema jurídico requiere un acto formal para que una norma comience a existir como derecho (verbigracia, su publicación), también requiere una declaratoria formal de invalidez para que una

\footnotetext{
de los sistemas jurídicos es una cuestión de hecho, que se identifica con su efectividad para regular las relaciones sociales de una comunidad. Si bien es cierto que la existencia de un sistema jurídico sin capacidad normativa es un contrasentido, también es cierto que el momento de la extinción del sistema no es determinable con exactitud. KELSEN sólo llegó a plantear una fórmula general: la existencia del sistema depende de un minimum de eficacia (cfr. HANS KelSEN. Págs. 137-140. En ob. cit. en nota al pie 3). HART fue más allá: la existencia de un sistema no puede verificarse en cortos períodos de tiempo, porque es lo suficientemente amplia y general como para tolerar interrupciones

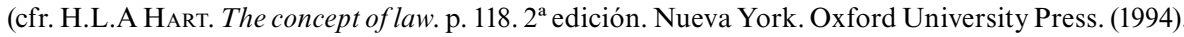
RAz ha sido, por último, el que ha problematizado más sobre el tema. Propone dos exámenes para determinar la existencia de un sistema jurídico: 1) el examen de efectividad: que es preliminar y sirve para determinar si en una sociedad existe algún sistema jurídico operante, asumiendo que aunque todas sus normas son relevantes, no todas tienen la misma importancia para asegurar la continuidad del sistema; y 2) el examen de exclusión: determina cuál es el sistema existente en una sociedad, pues puede ocurrir que más de uno esté rigiendo efectivamente. El examen de exclusión pone de relieve el hecho que es artificial pretender hacer un corte general en la existencia del sistema, y que lo realista parece ser asumir que a la vez que un sistema va volviéndose ineficaz, otro va ocupando su lugar en el espacio que la ineficacia del primero le deja. Una cosa es cierta, y es que RAz tiene razón al casar la identidad de los sistemas jurídicos con la identidad de las formas sociales que regulan, porque como hecho social el derecho es un epifenómeno de la cultura (cfr. Joseph Raz. Págs. 188-189, 203-208, 211. En ob. cit. en nota al pie 5).
} 
norma deje de existir como derecho ${ }^{10}$. De manera que respecto a cualquier norma preconstitucional que se pudiera considerar objetable de inconstitucionalidad sobrevenida, jurídicamente sólo puede decirse que según la Constitución del 2009 el derecho preconstitucional es válido mientras el Tribunal Constitucional Plurinacional no lo declare inconstitucional. Sólo este órgano puede emitir tal declaratoria, por cuanto la Constitución le ha reservado la competencia para ejercer el control de la constitucionalidad (arts. 196, parágrafo I y 202). Desde que esta competencia constituye una reserva material, ningún otro órgano del Estado puede arrogársela, como no sea violando la Constitución. Por tanto, en lo tocante al derecho preconstitucional, hay continuidad, no ruptura.

En cuanto a las competencias de los órganos constitucionales (con extensión a todo el aparato institucional del Estado), téngase presente que para extinguir un órgano constitucional la Constitución no necesita declararlo expresamente; su silencio al respecto basta para entender que no forma más parte de la estructura del Estado (extinción del órgano por derogación de su norma de regulación). Dicho esto, cuando la Constitución regula las competencias de los órganos constitucionales ya existentes, la continuidad del sistema jurídico se produce en la forma de una sucesión de competencias, imponiéndoles las que emanan de ella y derogando las que emanaban de la anterior Constitución. Por tanto, en las competencias de los órganos constitucionales tampoco hay ruptura, sino sucesión, por lo que no interrumpen sus funciones (incluyendo las de producción normativa), ya que la sucesión es consecuencia de la sola entrada en vigor de la Constitución.

Esto significa: 1) que transitoriamente los órganos constitucionales sucedidos del régimen anterior ejercen las competencias atribuidas por la Constitución del 2009 a sus sucesores, salvo aquellas que expresamente la Constitución ha reservado a los últimos; así, el presidente de la República

10 La presunción de validez no se agota en el enunciado de su pura literalidad, sino que ella es consecuencia de distinguir entre las condiciones de validez y las condiciones jurídico-positivas de invalidez, pues si bien el sistema impone condiciones para la validez de sus normas, el sistema puede, por razones de seguridad jurídica, negar efecto invalidatorio al incumplimiento de algunas de esas condiciones. Merkl llama a esto el cálculo del error, nombre con el que justifica que los sistemas positivos sopesen (calculen) el peso de las condiciones de validez y decidan que el incumplimiento de algunas de ellas (las de menor importancia) no acarree la invalidez del acto afectado. En consecuencia, si el sistema positivo niega efectos invalidatorios al incumplimiento de una condición de validez, entonces tal incumplimiento no es causante de invalidez, pero si el sistema no dice nada al respecto, entonces las condiciones de invalidez son las mismas que las de validez, porque, ante el silencio del derecho positivo el fenómeno de la invalidez vuelve a justificarse en la explicación lógica-filosófica de la validez de las normas. También es consecuencia de la presunción de validez que haya actos que sean inexpugnables por no haber en el sistema un órgano con competencia para declararlos inválidos. Es el caso, por ejemplo, de las decisiones de los máximos órganos jurisdiccionales, que son definitivas no por su intrínseca corrección racional con respecto a sus condiciones de validez, sino porque son irrevisables, y es esto lo que las hace incontrovertiblemente válidas. 
ejerce las competencias del presidente del Estado (art. 172), el Congreso Nacional las de la Asamblea Legislativa Plurinacional (art. 158), excepto la potestad para legislar sobre las materias expresamente reservadas por las disposiciones transitorias segunda y quinta al órgano sucesor, a saber, la Asamblea Legislativa Plurinacional que entre en funciones después de las elecciones del 6 de diciembre del 2009, etc.; y 2) que hasta el empalme con los órganos sucesores los órganos constitucionales sucedidos continúan funcionando de acuerdo con la conformación que traen del régimen anterior, ya que de la regla de irretroactividad de la Constitución vigente (art. 123) se deriva que debe ser respetado el período de funciones de sus actuales integrantes, excepto cuando la propia Constitución haya establecido una regla contraria, en cuyo caso debe preferirse por su especialidad; así, los magistrados del órgano judicial continúan en funciones hasta el vencimiento del plazo para el que fueron designados, con mucho que la Constitución vigente establezca períodos menores que los de la anterior, y que, desde luego, correrán para quienes sean designados conforme a ella; o en lo tocante a los órganos ejecutivo y legislativo conformados según el régimen anterior, si sus miembros no agotaran los períodos para los que fueron electos no se debe al hecho mecánico de pasar a una nueva Constitución, sino a que ésta expresamente ha reducido sus mandatos, como también expresamente los ha ampliado para los alcaldes, concejales y prefectos (disposición transitoria primera).

\section{LA SUPREMACÍA DE LA CONSTITUCIÓN Y LA NORMA INCORPORANTE: EL BLOgUE DE CONSTITUCIONALIDAD}

La supremacía de la Constitución es una cuestión de hecho: ella es la norma suprema del sistema jurídico en la medida de su efectividad para dotar de validez a la pluralidad de normas que lo integran. Sólo en este sentido la Constitución es la fuente de fuentes (norma normarum). La norma que si bien no regula directamente las condiciones de validez de todas las formas normativas del sistema, lo unifica al hacer que las normas que regulan la producción de cada forma concreta deriven, directa o indirectamente, de ella. Esta es la razón de la primacía constitucional, y de esto la cláusula de supremacía (art. 410, parágrafo II) es sólo una descripción, no su fundamento. Fundar la primacía de la Constitución en su cláusula de supremacía es incurrir en un razonamiento circular: es afirmar que la Constitución es suprema porque ella dice que lo es.

La supremacía de una constitución se funda en el dato fáctico de su acatamiento por parte de los poderes públicos. De ahí que, en términos de eficacia, sin control de la constitucionalidad no haya constitución; sólo la 
adjudicación de sus normas da cuenta de la subordinación de los poderes públicos a su imperio ${ }^{11}$.

A partir de la unidad del sistema jurídico, la supremacía de la Constitución significa: 1) que en todo proceso de producción normativa debe aplicarse las normas constitucionales con preferencia a cualquier otra norma, en los términos reglados por el sistema (verbigracia, el incidente de inconstitucionalidad tratándose de la producción de una norma individualizada, como una sentencia, artículo 132 de la Constitución); 2) que la pluralidad de normas que forma el sistema debe interpretarse conforme a la unidad de las normas constitucionales: dado que ellas fundamentan la validez de todo el sistema jurídico, las normas que lo integran no pueden ser antinómicas entre sí, y si se produce una antinomia, el conocimiento jurídico está obligado a eliminarla, pues es un imposible lógico formular como descripción de normas dos disposiciones antinómicas; 3) que ante interpretaciones distintas debe preferirse aquella cuya disconformidad con las normas constitucionales no sea manifiesta (principio de conservación de la norma) ${ }^{12}$; y 4) que la jurisprudencia constitucional tiene preeminencia sobre las fuentes ordinarias, como consecuencia de que la Constitución ha reservado para el Tribunal Constitucional Plurinacional la interpretación autoritativa de las normas constitucionales (arts. 196, parágrafo I y 202).

Ahora bien, son normas constitucionales no sólo las que integran el texto formal de la Constitución, sino también los tratados sobre derechos humanos

11 En este sentido, parece que RAz está en lo correcto cuando propone un criterio jurisprudencial como regla de reconocimiento de los sistemas jurídicos, pues el acatamiento de las decisiones de los tribunales es señal de la eficacia de un sistema (cfr. Joseph Raz. Pág. 200. En ob. cit. en nota al pie 5).

12 La conservación de la norma es una práctica antigua en la justicia constitucional. En su cuna, la Corte Suprema de Estados Unidos, el principio comenzó a afirmarse antes aún de inaugurarse el control de constitucionalidad. En Hylton vs. United States (1796) CHASE dijo que si los jueces tenían el poder de declarar inconstitucional una ley, él era libre de declarar que nunca lo ejercería sino en un caso muy claro (3 U.S. 171, 1796). Y en Calder vs. Bull (1798) Iredell afirmó que el control de la constitucionalidad era un poder de una "naturaleza enorme y delicada" al que la Corte no debía recurrir "sino en un caso claro y urgente" (3 U.S., 3 Dall, 386, 1798). Ya habiendo hecho ejercicio del control de constitucionalidad, Marshall lo aplicó en Murray vs. Schooner Charming Betsy (1804): "una ley del Congreso nunca debe ser interpretada de tal manera que resulte violatoria del derecho internacional si es que hay alguna otra interpretación posible" (6 U.S., 2 Cranch, 64, 1804, p. 118). En Darmouth College vs. Woodward (1819) la Corte comenzó a esbozar su formulación actual: "ha de presumirse a favor de la validez [de la ley] hasta que su violación a la Constitución sea probada más allá de toda duda razonable" (17 U.S., 4 Wheat, 518, 1819). En Parsons vs. Bedford (1830) STORY terminó de formularlo, dando lugar a la denominación de avoidance canon con que se conoce el principio en el derecho americano, y que por definición (regla de evitamiento) dice de su sentido: "ningún tribunal debe, ni siquiera involuntariamente, construir una interpretación que suponga una violación de la Constitución, a menos que los términos de la ley lo hagan inevitable" (28 U.S. 433, 1830. Pág. 448). Al parecer, el principio de conservación de los actos normativos se originó en el derecho privado. Habría sido formulado como respuesta a los conflictos planteados por contratos con cláusulas ambiguas. De esto hay antecedentes tan antiguos como el Digesto: "en casos ambiguos, lo más conveniente es aceptar que la cosa de que se trata más bien sea válida a que perezca" (Digesto, Ley 12, Título 5, Libro 34: Quoties in ambigua oratio est, commodissimum est, id accipi, quo res, de qua agitar, magis valeat quam pereat). 
y las normas de derecho comunitario, que sumados al texto formal conforman una unidad normativa, a saber, el bloque de constitucionalidad ${ }^{13}$ (art. 410, parágrafo II de la Constitución). De manera que formalmente la validez del sistema jurídico boliviano, por efecto de la incorporación normativa prevista por el artículo 410. II, deriva de los tratados sobre derechos humanos y las normas de derecho comunitario en el mismo grado que deriva del texto formal de la Constitución. Por derivar de una incorporación normativa, cuando se trata de la violación de normas incorporadas, el vicio de constitucionalidad no se produce por el hecho de la violación de dichas normas, sino por la violación de la norma incorporante, responsable de darles rango constitucional $^{14}$. Debido a la continuidad del sistema jurídico, integran el bloque de normas constitucionales los tratados sobre derechos humanos y normas de derecho comunitario ratificados por el Congreso Nacional durante la vigencia de la anterior Constitución. Por esta misma razón, la incorporación incluye también a las normas de derecho comunitario derivado y producido con anterioridad a la entrada en vigor de la Constitución del 2009.

En lo atinente a los tratados sobre derechos humanos, el artículo 410. II supone asumir en el texto expreso de la Constitución la jurisprudencia del Tribunal Constitucional, que tomó el artículo 35 de la anterior Constitución como "permiso expreso" para la incorporación de normas al bloque de constitucionalidad, haciéndolo puerto de entrada de derechos y garantías tácitamente enunciadas, pero no consignadas literalmente en su texto, y que por igual nacían de la soberanía del pueblo y la forma republicana de gobierno. Por lo demás, dicha construcción jurisprudencial también se fundaba en el texto formal de la Constitución, pues la declaración de inconstitucionalidad de una norma contraria al bloque se sustanciaba en razón de la violación de su artículo $35^{15}$.

13 La expresión "bloque de constitucionalidad" es francesa. Dice de las normas que se aplican para controlar la constitucionalidad del derecho ordinario, del mismo modo que la expresión "bloque de legalidad" dice de las normas ordinarias que se aplican para controlar la legalidad de los actos administrativos. La expresión surgió en los años setenta, como una explicación doctrinal al hecho que el Consejo Constitucional verificase la constitucionalidad de las leyes no sólo según la Constitución vigente de 1958, sino también según la Declaración de los Derechos del Hombre y del Ciudadano de 1789 y según el Preámbulo de la Constitución de 1946. El Consejo Constitucional razonó que, a pesar de tratarse de cuerpos normativos formalmente distintos, el Preámbulo de la Constitución de 1958 los incorporaba como normas constitucionales, en la extensión aludida por dicho texto ("El pueblo francés proclama solemnemente su adhesión a los derechos humanos y a los principios de la soberanía nacional tal y como fueron definidos por la Declaración de 1789, confirmada y completada por el Preámbulo de la Constitución de 1946”, Preámbulo, Constitución de 1958). Según la interpretación del Consejo Constitucional, el Preámbulo de la Constitución de 1958 es una norma incorporante.

14 Propongo la denominación de "norma incorporante" porque sus efectos son los de incorporar a la Constitución normas que no están en su texto formal. En este sentido, el artículo 410. II produce constitucionalmente los mismos efectos que contractualmente producen las cláusulas que establecen que determinados documentos son partes integrantes de un contrato. La entidad jurídica de estas cláusulas es, como la del artículo 410. II, también la de una norma incorporante.

15 Según la interpretación del Tribunal Constitucional, el artículo 35 de la antigua Constitución era 
Que los tratados sobre derechos humanos sean normas constitucionales supone la incorporación de su significado jurídico según como haya sido definido por los órganos autorizados para su interpretación. Por esto, los precedentes de la Corte Interamericana de Derechos Humanos son parte del bloque de constitucionalidad. Es consecuencia de que la Convención Americana sobre Derechos Humanos ${ }^{16}$ otorgue competencia a la Corte para aplicar e interpretar la Convención (art. 62) y para producir decisiones autoritativas al respecto (art. 67). En consecuencia, negar el carácter vinculante de los precedentes supondría violar la propia Convención, en la medida que supone

una norma incorporante. La primera vez que se hizo mención al bloque de constitucionalidad fue en la STC 95/2001-RDI (21 de diciembre). En ella, aunque los límites del bloque ya estaban claros (los tratados sobre derechos humanos), no se argumentaba sobre su fuente positiva, de hecho, el artículo 35 ni siquiera mereció mención. Ya para la STC 1662/2003-RAC (17 de noviembre) el artículo 35 era tomado como norma incorporante, aunque el Tribunal desarrolló mejor el argumento de la incorporación en la STC 45/2006-RDI ( 2 de junio). En ésta, sin embargo, el Tribunal comenzó usando un lenguaje cercano al concepto de constitución material, afirmando que las normas del bloque eran tales por virtud de sus "cualidades intrínsecas". Lo cierto es que las cualidades intrínsecas (materia) que debía tener una norma para integrar el bloque de constitucionalidad no las decidía el Tribunal Constitucional -como tampoco las decide el Consejo Constitucional francés-, sino la propia Constitución a través de su norma incorporante. El bloque de constitucionalidad, así, trabaja con el concepto de constitución formal. Durante el proceso de cambio de la Constitución, se presentó a la Asamblea Constituyente un artículo cuyo parte pertinente decía: "Las normas de derecho internacional sobre derechos humanos son por su materia normas constitucionales". Su motivación era la siguiente: “23. Jerarquía material. Según el artículo propuesto las normas de derecho internacional sobre derechos humanos son, por su materia, normas constitucionales. Esto no debe prestarse a equívocos. Las normas sobre derechos humanos, en la medida que son normas de derecho internacional, son normas formalmente superiores a las leyes e inferiores a la Constitución. Aquí el artículo se refiere a aquellas normas que, sin ser formalmente constitucionales, son utilizadas para el control de la constitucionalidad de otras normas. Es decir, aun las normas que por su carácter formal resultan infraconstitucionales, son consideradas constitucionales por su materia. El artículo no debe interpretarse como una alusión al concepto de constitución material. Constituciones materiales han existido siempre, y existirán siempre que el poder necesite organizarse. Son constituciones materiales las normas que sirven de fundamento de validez a otras normas; lo que lleva de vuelta a las nociones de jerarquía lógica y de cadena de validez. La norma de que deriva todo el sistema jurídico es su constitución material, pues, en un sentido material, constitución es toda norma que posibilita la producción jurídica. Sin embargo, no es en el sentido material que importa a una democracia tener una constitución, sino en el formal: esta es la constitución que garantiza la sumisión de los poderes públicos y coloca al pueblo en una posición de primacía. He aquí el concepto formal de constitución como norma suprema del ordenamiento jurídico y con vocación de permanencia. Por ello, el artículo propuesto opera como una remisión normativa que hace la constitución formal a normas de fuente internacional que materialmente versan sobre los derechos humanos. Así, el artículo propuesto introduce al texto formal de la Constitución la construcción jurisprudencial de su actual artículo 35, pero ampliándola en el sentido que son las normas de derecho internacional sobre derechos humanos, y no sólo los tratados, que forman parte del bloque de constitucionalidad. En tanto construcción jurisprudencial, la actual extensión del bloque de constitucionalidad podría ser modificada por una construcción jurisprudencial futura, pues aun donde impera el respeto a los precedentes pueden los jueces y tribunales apartarse inclusive de los generados por ellos mismos, siempre que lo fundamenten debidamente" (Horacio ANDALUZ. El derecho internacional en el sistema de fuentes: propuesta de artículos para la nueva Constitución de Bolivia. Pág. 97. Revista Boliviana de Derecho. 6. (2008). reproducido en VIII Anuario Mexicano de Derecho Internacional 2008 y en 15 Anuario de Derecho Constitucional Latinoamericano 2009).

16 Ratificada por la Ley 1430 del 11 de febrero de 1993 
desconocer la calidad de órgano autoritativo que tiene la Corte $^{17}$. Obedecer los precedentes es también una exigencia práctica. Supone que los Estados se comporten según las normas que serán usadas para su enjuiciamiento.

Hasta aquí, se tiene que los tratados sobre derechos humanos son normas de jerarquía constitucional, siendo su supremacía (jerarquía positiva) el criterio que regula sus relaciones con las normas ordinarias del sistema jurídico. Pero la Constitución también regula las relaciones entre las normas contenidas en estos tratados y las normas contenidas en su texto formal. Estas relaciones son regidas por el criterio de especialidad. De ahí que, de presentarse una antinomia entre una norma del texto formal de la Constitución y una contenida en un tratado sobre derechos humanos, debe interpretarse el supuesto de hecho de la norma del texto formal como siendo lo suficientemente general como para cobijar el supuesto especial de la norma de fuente internacional, eliminándose la antinomia con la aplicación preferente de esta última ${ }^{18}$.

Repárese en el contenido del artículo 13. IV de la Constitución: "Los tratados y convenios internacionales ratificados por la Asamblea Legislativa Plurinacional, que reconocen los derechos humanos y que prohíben su limitación en los estados de excepción, prevalecen en el orden interno. (...)”. El texto "y que prohíben su limitación en los estados de excepción" podría llevar

17 Sobre el carácter vinculante de los precedentes véase el punto II. 4. El artículo 68.1 de la Convención ("Los Estados partes en la Convención se comprometen a cumplir la decisión de la Corte en todo caso que sean partes"), no se refiere al valor normativo de los precedentes, sino al carácter vinculante del fallo, el que, obviamente, sólo obliga a las partes en litigio. En consecuencia, el artículo 68.1 no niega el carácter vinculante general de los precedentes de la Corte.

18 Es un equívoco decir que algunas normas constitucionales tienen rango "supraconstitucional" para referirse a que se aplican con preferencia a otras normas también constitucionales. Tal designación confunde las relaciones estructurales del sistema jurídico con los modos específicos de relacionamiento intranormativo. Por ello que no conciba más modo de relacionamiento intranormativo que el jerárquico, y por eso que la aplicación preferente la entienda en términos de jerarquía, como la propia palabra "supraconstitucional" mienta. Si la aplicación preferente se entiende en términos de jerarquía, entonces la "supraconstitucionalidad" sólo puede significar una de las dos siguientes consecuencias: 1) o bien es una invocación al naturalismo, con lo cual las normas "supraconstitucionales" expresarían una teoría acerca del conocimiento moral, pero no serían derecho; 2) o bien conlleva la ordinarización de la constitución, pues si hay normas superiores a ella, entonces no es la norma suprema, y la verdadera norma fundacional, o sea la verdadera Constitución, estaría conformada por las llamadas normas "supraconstitucionales", y en esa medida sólo ellas condicionarían la validez de todo el ordenamiento jurídico, comenzando con las normas de lo que entonces habría que denominar la "constitución ordinaria". Ahora bien, si con el término "supraconstitucionalidad" no se quiere hacer referencia a una superior jerarquía, sino al hecho de que ciertas disposiciones tienen mayor relevancia ontológica que otras, como ocurre con los principios, haciendo que las primeras influyan en la determinación del significado jurídico de las segundas, entonces la "supraconstitucionalidad" sería una nueva denominación para un concepto ya conocido, a saber, el ámbito de aplicación material propio de cada disposición. En el caso de los principios, su mayor ámbito de acción es consecuencia de que los mismos reciben tal denominación porque de ellos puede deducirse otros contenidos, sea por su mayor relevancia teleológica o lo sea por su importancia axiológica. En cualquier caso, no es que se trate de normas superiores, sino de contenidos de mayor relevancia ontológica, que, por ello mismo, participan en la determinación del significado jurídico de otras normas. 
a entender que sólo prevalecerán en el orden interno los tratados de derechos humanos que contengan tal prohibición. Pero esta no es una interpretación posible, porque resulta antinómica respecto a lo establecido por el artículo 410. II, que hace que cualquier tratado sobre derechos humanos tiene jerarquía constitucional. En consecuencia, en términos de significado jurídico, de lo que dicho texto estaría predicando es de la especialidad de las normas que menciona en relación con las demás normas constitucionales (tanto las del texto formal como las incorporadas). Como la unidad del sistema jurídico impide sostener que el artículo 13. IV esté diciendo lo que su tenor literal, en efecto, dice, debe rescatarse su sentido normativo apelando a su especialidad, pues es lo que permite demostrar que no contradice lo dispuesto por el artículo 410. II. Así, 1) el artículo 410. II establece la supremacía constitucional llana de todos los tratados sobre derechos humanos, pero 2) eso no es antinómico con que durante el estado de excepción la aplicación de tales tratados se rija por la regla especial del artículo 13. IV reconstruido: prevalecen entre todas las normas constitucionales de la materia (supremacía constitucional llana), aquellas que prohíban la limitación de los derechos humanos durante el estado de excepción (aplicación del criterio de especialidad entre normas del mismo rango).

Que el criterio de especialidad regula las relaciones entre las normas constitucionales sobre derechos humanos, está claro en el texto expreso del artículo 256. I: los tratados sobre derechos humanos que "declaren derechos más favorables a los contenidos en la Constitución, se aplicarán de manera preferente sobre ésta". Al igual que en el caso del artículo 13. IV, aquí la preferencia no está en función de la jerarquía, porque todas las normas son del mismo rango, sino de la especialidad.

Con forma de regla de interpretación, el artículo 256. II introduce al sistema una norma sobre la producción jurídica (fuente). Así, establece que los derechos reconocidos en la Constitución se interpretarán de acuerdo con los tratados internacionales sobre derechos humanos "cuando éstos prevean normas más favorables". Excepto la parte entrecomillada, el mismo texto está en el artículo 13. IV. Otra vez, para ambos artículos debe entenderse que la regla de interpretación supone la especialidad de los tratados de derechos humanos respecto del texto formal de la Constitución, tomando como criterio específico de especialidad su carácter más favorable para los derechos humanos. Que la mención expresa al carácter más favorable no esté en el texto del artículo 13. IV no quiere decir que no sea parte de su significado jurídico: la razón de ser de las constituciones es instituir gobiernos de poderes limitados, por lo que la regla general para su interpretación es que debe leérsela a favor de las libertades ciudadanas.

También son normas constitucionales las de derecho comunitario (sistemas normativos producidos por las comunidades de integración entre Estados). 
Por su fuente de producción, estos sistemas están compuestos por normas de derecho originario y de derecho derivado. Las primeras son normas de derecho internacional convencional producidas por los Estados miembros de la comunidad de integración, y equivalen a la constitución de la comunidad. Las segundas son producidas por los órganos de gobierno de las comunidades. Son normas cuya validez deriva de los tratados constitutivos, pues los poderes normativos resultan de las competencias que, a través de los tratados constitutivos, los Estados miembros han atribuido a los órganos comunitarios.

A propósito del derecho comunitario derivado, según el artículo 410. II (norma incorporante), el requisito para que una norma integre el bloque de constitucionalidad es que haya sido ratificada por el país. En el lenguaje de la Constitución, la ratificación significa 1) el acto de derecho interno mediante el cual el órgano legislativo autoriza al ejecutivo a celebrar tratados (art. 158. I. 14); 2) el acto de derecho internacional que expresa la manifestación del consentimiento del Estado en obligarse convencionalmente ante sus pares (art. 255. I $)^{19}$; y 3) la incorporación de los tratados al derecho interno, para que sean aplicables en este orden ${ }^{20}$ (art. 257. I). Pues bien, la norma incorpo-

19 En cuanto a esta acepción, la mención a la ratificación en el texto de la Constitución debe entenderse referida al género de actos aceptados en el derecho internacional para manifestar tal consentimiento. Así, la ratificación se equipara a la firma, al canje de instrumentos constitutivos del tratado, a la aceptación, a la aprobación, a la adhesión o a cualquier otra forma convenida en un tratado como medio para obligarse por él, pues todas ellas son las formas usadas en el derecho internacional. De esta manera, integran el bloque de constitucionalidad todas las normas respecto de las cuales el Estado boliviano haya manifestado su consentimiento en obligarse, aun cuando no sea bajo la forma específica de la ratificación.

20 En este tema la Constitución del 2009 arrastra la herencia dualista de la Constitución de 1826. Así, para ser aplicables por jueces y tribunales, las normas de derecho internacional tienen que ser objeto de un acto de voluntad del legislador estatal que las transforme en normas de derecho interno. El acto de transformación supone la creación de la norma a cargo del sistema estatal de fuentes. Sobre este tema, se propuso a la Asamblea Constituyente adoptar una posición monista. El texto del artículo decía: "Las normas de derecho internacional que obligan al Estado integran el derecho nacional. Una vez en vigor según sus propias disposiciones, los tratados en que Bolivia es parte establecen derechos y deberes de aplicación directa”. Nótese que el artículo propuesto incorporaba al orden interno todas las formas que revisten las normas internacionales (tratados, costumbres, resoluciones de organismos internacionales). En lo que respecta a la incorporación de los tratados, los fundamentos eran los siguientes: "11. Descripción general. Este artículo norma la integración de las normas de derecho internacional al derecho interno. Sus referentes de derecho comparado son las constituciones alemana (art. 25) y griega (art. 28.1). La primera norma de esta índole fue formulada en la Constitución de Weimar (1919): "las reglas universalmente reconocidas del derecho internacional forman parte integrante del derecho alemán" (art. $4^{\circ}$ ). Detrás de las normas de integración está el debate sobre el postulado epistemológico de la unidad del sistema jurídico. La integración de las normas de derecho internacional supone la primacía de este orden. Así, las obligaciones asumidas por el Estado en virtud de una norma internacional priman sobre las de su constitución. Por su naturaleza, esta es una norma sobre las fuentes de producción del derecho estatal; por su forma, una norma de procedimiento. El derecho internacional deja la determinación de los procedimientos de integración a las constituciones nacionales. 12. Justificación de la fórmula. Se considera que la fórmula empleada es idónea y suficiente, pues, de un lado, es claro que integran el derecho nacional las normas de derecho internacional que obligan al Estado, donde el término obligan ciertamente es inequívoco, frente a la fórmula generalmente reconocidas utilizada por ciertas constituciones. A su vez, la fórmula establecen derechos y deberes de aplicación 
rante procede bajo la comprensión de este triple alcance del término, y ello es exigible, en efecto, para los tratados sobre derechos humanos y las normas de derecho comunitario originario, porque en ambos casos se trata de normas de derecho internacional convencional, ergo regidas por la Constitución tanto en su proceso de formación (participación de los órganos constitucionales) como en las condiciones para su aplicación en el derecho interno. Empero, tratándose de normas de derecho comunitario derivado, debe tenerse en cuenta que su formación y eficacia en el derecho interno dependerán de lo pactado en los tratados constitutivos pertinentes, que bien pueden disponer que tengan eficacia directa o que primero deban ser incorporadas formalmente al orden interno, ya sea por la vía usual de la ratificación legislativa o por mecanismos más expeditivos ${ }^{21}$. Por tanto, exigir para las normas de

directa es suficiente, por cuanto jurídicamente importa que dichas normas pueden ser invocadas y aplicadas como cualquier otra norma de derecho interno. (...). 17. Integración de tratados. El artículo propone la integración automática de los tratados en vigor. Así se evita que la vigencia interna y la vigencia internacional de un tratado se produzcan en momentos diferentes, como puede ocurrir en los sistemas de recepción formal, en que el acto legislativo que autoriza a vincularse internacionalmente es también el instrumento que transforma la norma internacional en nacional. Algunos sistemas constitucionales requieren la publicidad de los tratados para su incorporación al derecho interno, pero aun siendo este requisito de más fácil cumplimiento que la transformación por un acto legislativo, no evita la producción de desfases temporales entre la vigencia interna y la vigencia internacional de los tratados. A su vez, el hecho que la publicación deba ser del texto íntegro del tratado (lo que incluye sus anexos, reservas, declaraciones interpretativas, adhesiones, retiros, notificaciones entre partes sobre su denuncia o su suspensión, así como publicar en un futuro todo acto relativo al tratado), hace que sea más práctico descentralizar en los operadores jurídicos la obligación de conocer el derecho. Por lo demás, el artículo se refiere a los tratados en los que Bolivia sea parte, lo que responde a una exigencia de coherencia en el lenguaje tratándose de una norma de integración, pues sólo son incorporables los tratados en vigor internacional para el Estado, siendo respecto de éstos que se dice que un Estado es parte (en cambio, se dice Estado negociador en las fases de negociación, adopción y autenticación de un tratado, y Estado contratante en las de manifestación del consentimiento y perfeccionamiento del mismo). Según el artículo propuesto, los tratados pasan a formar parte del derecho nacional desde su entrada en vigor. Aunque la entrada en vigor de un tratado es asimilable conceptualmente al momento en que una ley entra en vigencia, existen determinadas particularidades diferenciadas en el plano operativo. Así, respecto de cada tratado en particular, en principio debe considerarse que entra en vigor según sus propias disposiciones o, en su defecto, tan pronto haya constancia del consentimiento de todos los Estados negociadores en obligarse por el mismo. A su vez, la pertinencia de determinar la fecha de entrada en vigor con respecto a cada Estado, viene de que en el derecho internacional se conoce el vigor general (cuando entra en vigor para todos los Estados negociadores) y el vigor particular (cuando entra en vigor respecto de un Estado, comúnmente porque hizo constar su consentimiento en obligarse en fecha posterior a la entrada en vigor de un tratado)" (Horacio Andaluz. Págs. 85-86, 91-92. En ob. cit. en nota al pie 15).

21 La aplicación del derecho comunitario derivado en el derecho interno depende de cada acuerdo de integración. Por ejemplo, el artículo 189 del Tratado de la Comunidad Europea establece que los reglamentos son directamente aplicables en los Estados miembros, mientras que las directivas no lo son (éstas obligan a los Estados miembros en cuanto al resultado que debe conseguirse, dejándoles en libertad para elegir la forma y los medios de alcanzarlos). En el caso del Protocolo de Ouro Preto (Mercado Común del Sur), las decisiones, resoluciones y directivas deben ser incorporadas en los ordenamientos jurídicos nacionales mediante los procedimientos previstos en la legislación de cada país (art. 42). Por tratarse de un proceso de integración, cada uno de los Estados miembros ha regulado procedimientos menos formales que la ratificación legislativa. 
derecho comunitario derivado el cumplimiento de requisitos distintos a los convenidos en los tratados de derecho comunitario originario, supondría 1) comprometer la fe internacional del Estado en la medida de la violación que hubiese del tratado ( pacta sunt servanda); y 2) violentar la propia Constitución, porque como el derecho comunitario originario forma parte del bloque de constitucionalidad, incumplir sus normas implica violentar la norma incorporante (art. 410, parágrafo II).

Para tomar el caso de la Comunidad Andina de Naciones, los artículos 17 y 21 del Acuerdo Subregional Andino (Acuerdo de Cartagena) atribuyen al Consejo Andino de Ministros de Relaciones Exteriores y a la Comisión de la Comunidad Andina competencia para emitir derecho comunitario derivado en la forma de decisiones, las mismas que forman parte del ordenamiento jurídico andino (arts. 17 y 25). Como miembro de la Comunidad, Bolivia es parte del Tratado de Creación del Tribunal de Justicia de la Comunidad Andina y de su Protocolo Modificatorio ${ }^{22}$ (derecho comunitario originario), del que interesan 1) el artículo $1^{\circ}$, literal c, que reitera que las decisiones del Consejo Andino y de la Comisión forman parte del ordenamiento jurídico de la Comunidad; 2) el artículo $2^{\circ}$, que dispone que las decisiones obligan a los Estados miembros desde la fecha de su aprobación por el órgano que las emitió; y 3) el artículo $3^{\circ}$, que reconoce a las decisiones eficacia directa en los países miembros a partir de su publicación en la Gaceta Oficial del Acuerdo, excepto cuando su propio texto disponga que para ser aplicable es necesaria su incorporación en el derecho interno mediante acto expreso. Por tanto, siempre que no se trate de esta excepción, las decisiones de la Comunidad Andina integran el bloque de constitucionalidad sin necesidad de ratificación.

\section{LA LECTURA JURÍDICA DE LA CONSTITUCIÓN: RECONSTRUCCIÓN DE SU CLÁUSULA DE INTERPRETACIÓN}

Las reglas de interpretación positivadas son metanormas (fuentes). Ellas, al reglar la reconstrucción interpretativa de las disposiciones jurídicas, están sujetando sus condiciones de validez al método de interpretación positivado por la regla. Esto es lo que ocurre con la "cláusula de interpretación", nombre con el que se hace referencia al artículo 196. II de la Constitución, mientras que por su "reconstrucción" se entiende la expresión de su significado jurídico una vez interpretada. En tanto interpretación de una cláusula de interpretación, el ejercicio consiste en tomar la cláusula como disposición continente y pasar de la expresión literal de su texto a las normas jurídicas que realmente contiene. Por toda justificación del ejercicio, baste advertir que por la interpretación

22 Ratificado por Ley 1872 de 15 de junio de 1998. El instrumento de ratificación se depositó el 18 de septiembre de 1998. El Protocolo Modificatorio entró en vigor en agosto de 1999. 
de su cláusula de interpretación pasará a su turno todo el contenido de la Constitución, incluyendo sus normas sobre la producción jurídica. De manera que en gran medida esta cláusula es "la constitución de la constitución". Dice la cláusula de interpretación: "En su función interpretativa, el Tribunal Constitucional Plurinacional aplicará como criterio de interpretación, con preferencia, la voluntad del constituyente, de acuerdo con sus documentos, actas y resoluciones, así como el tenor literal del texto".

La frase "con preferencia" es la que da a la cláusula su significado jurídico, más allá del mandato literal al intérprete de preferir la "voluntad del constituyente" 23 y el "tenor literal del texto" 24 .

En efecto, "con preferencia" significa: 1) que los criterios proporcionados por la cláusula deben tener para el intérprete preeminencia sobre otros criterios de interpretación (sentido obvio de la cláusula). 2) Que entre la interpretación según "la voluntad del constituyente" y la interpretación según "el tenor literal del texto" no existe prelación, siendo que en la práctica lo segundo puede no expresar lo primero, y aun presentar divergencias. 3) Que

23 La frase hace referencia a la interpretación histórica. Esta propugna: 1) que el significado de las disposiciones legales debe justificarse en la voluntad del legislador; 2) que la voluntad del legislador es un buen justificativo porque la misma fue expresión de las fuentes materiales que desembocaron en la promulgación de la norma; 3) que un buen referente de las fuentes materiales, como acervo condicionante de la intención legislativa, debiera encontrarse en los trabajos preparatorios y precedentes inmediatos de los cuerpos legales, pues ellos pueden ser útiles para investigar las razones sociales y políticas en que estuvo inmersa la actividad legislativa (de ahí que la cláusula de interpretación remita a encontrar la "voluntad del constituyente" en "sus documentos, actas y resoluciones"); y 4) que, por ello mismo, el método no ata a lo que el legislador quiso decir, sino a las razones que lo llevaron a decir lo que dijo, como fuente de justificación del significado jurídico de una proposición (esto último ya es un alejamiento del planteamiento decimonónico original que trabajaba con una visión subjetiva respecto del contenido de las proposiciones jurídicas, obligando al intérprete a atar el significado de las normas a la voluntad de la autoridad normativa que las dictó, mientras que hoy se acepta que las normas son autónomas e independientes de la voluntad de su creador y, por consiguiente, del sentido que éste quiso atribuirles).

24 La frase se refiere a la interpretación gramatical, sobre la que cabe puntualizar lo siguiente: 1) que por ella se entiende la tarea de precisar el significado de una disposición normativa haciendo un análisis lingüístico de las palabras, de los enunciados formados por ellas, del texto formado por los enunciados y del contexto extralingüístico en que discurre la disposición; 2) se entiende que cualquier análisis lingüístico se hace con referencia a las particulares acepciones usadas en cualquier campo del saber, de modo que tratándose de proposiciones de derecho el análisis lingüístico deberá considerar el sentido especializado que algunas palabras tienen en el marco del sistema jurídico, y cuando las palabras empleadas carezcan de un significado propio en el derecho, habrá de tomarse su sentido ordinario; 3) no supone que siempre deba acudirse a la interpretación, sino sólo cuando el texto no tiene un lenguaje claro, y donde por tal debe entenderse el que posee un significado convencionalmente aceptado; así, la antigua sentencia in claris non fit interpretatio se sigue aplicando, pero con un sentido renovado; 4) la sentencia que se acaba de citar tiene el sentido de una salvaguarda para evitar la interpretación contraliteral, es decir, aquella que es contraria al significado claro de una proposición; y 5) llevada a la adjudicación constitucional, la prohibición de interpretación contraliteral puede más que el principio de conservación de la norma ("al juez no le está permitido mediante la interpretación conforme con la constitución darle un significado diferente a una ley cuyo tenor y sentido resulta evidente": Jürgen SchwABE. Cincuenta años de jurisprudencia del Tribunal Constitucional Federal alemán. Pág. 3. $1^{\text {a }}$ edición. Montevideo. Fundación Konrad Adenauer. (2003). 
la preeminencia asignada por la cláusula a ambos criterios no es razón excluyente de otros resultados interpretativos, a los que pueda arribarse mediante la aplicación de criterios distintos. "Con preferencia" tiene de suyo un claro sentido normativo: autoriza al intérprete a servirse de otros criterios, con relación a los cuales dará preferencia a los mencionados en la cláusula. Por tanto, la cláusula no puede prohibir valerse de los resultados interpretativos obtenidos por criterios autorizados pero no enunciados expresamente. Con esto, el asunto pasa por saber bajo qué argumentos se pueden excluir los resultados contradictorios. Y 4) que así como no significa una razón excluyente, "con preferencia" tampoco significa valor confirmatorio, en el sentido que el uso de los resultados interpretativos obtenidos por criterios no mencionados estaría condicionado a su carácter confirmatorio de los resultados obtenidos acudiendo a "la voluntad del constituyente" o al "tenor literal del texto". Esta sería una interpretación contraliteral, es decir, una interpretación que no respeta el significado convencionalmente aceptado de una proposición, en que "preferir" y "confirmar" no son sinónimos.

Así, es cierto que la cláusula remite al intérprete a los criterios de interpretación mencionados, pero lo que en derecho debe entenderse es que tal mandato no es imperativo en el sentido de obligarlo a usar uno o ambos criterios, sino de obligarlo a justificar la decisión de no aplicar ninguno de ellos, cuando existan razones excluyentes para no hacerlo. Es decir, razones cuyas peculiaridades materiales o formales las hagan imperar sobre otras razones y sean determinantes en la decisión de no aplicar los métodos mencionados en la cláusula de interpretación ${ }^{25}$.

En este sentido, los límites naturales de los métodos impuestos en la cláusula de interpretación actúan como razones excluyentes materiales de la obligación del Tribunal Constitucional Plurinacional de emplearlos. De esta manera, no puede acudirse a la "voluntad del constituyente" cuando sus "documentos, actas y resoluciones" simplemente no se pronuncian sobre la disposición en análisis o, pronunciándose, su interpretación no conduzca a ningún resultado o conduzca a varios resultados posibles; como tampoco puede acudirse al "tenor literal del texto" cuando el texto lleve al mismo tipo de resultados (o ninguno o varios posibles). De lo dicho deriva que cada criterio está limitado por las propias razones que lo justifican como tal. No hay criterio que no pueda sucumbir por agotamiento interno. De hecho, ningún criterio de interpretación está libre de no conducir a ningún resultado, como no está libre de conducir a varios resultados posibles. Para lo primero, recurrir a un criterio distinto será materia obligada. Para lo segundo, el concurso de interpretaciones posibles sólo podrá ser resuelto con un criterio distinto al

25 El concepto de "razones excluyentes para la acción" es de RAz (cfr. JosEPH RAz. Practical reason and norms (reimpresión). Págs. 35 y ss. Nueva York. Oxford University Press. (2002). 
que lo originó. Lo cierto es que cuando un criterio sucumbe por agotamiento interno, son sus propias limitaciones las que devuelven al intérprete la plenitud de su libertad hermenéutica. Y por ello tal agotamiento constituye una razón excluyente material. En este caso es la propia materia o contenido del criterio lo que excluye la posibilidad de aplicarlo.

El agotamiento de los criterios de interpretación no es un tema controversial para la teoría general del derecho, ya que al asumir con naturalidad que una norma puede tener varias interpretaciones posibles, también asume que no hay un único criterio racional para justificar el significado de una proposición jurídica. Siendo así, el abordamiento del tema consiste en establecer si la propia ordenación del sistema jurídico brinda argumentos que operen como razones excluyentes formales ante el concurso de interpretaciones posibles. Es decir, si la teoría general del derecho proporciona argumentos para que el intérprete inaplique la "voluntad del constituyente" o el "tenor literal del texto", con vista a los aspectos formales del sistema jurídico.

La respuesta pasa, primero, por la unidad del sistema jurídico. En efecto, 1) para la teoría general del derecho el sistema jurídico forma una unidad en la medida que la validez de la pluralidad de sus normas puede ser reconducida hacia una única norma mayor como fuente universal de validez. Ahora bien, para que un sistema jurídico forme una unidad, la norma que le provee validez debe también formar una unidad: lo que se traduce en que el seno de la Constitución no puede albergar antinomias (en la interpretación constitucional esto se conoce como principio de unidad de la Constitución). Hasta aquí se tiene que, con cláusula de interpretación o sin ella, una interpretación constitucional posible es aquella que se justifica en la unidad de la Constitución o, en términos negativos, que debe rechazarse aquella que quiebre la unidad del sistema, aun cuando fundada en la "voluntad del constituyente" o el "tenor literal del texto". 2) Al fundar un sistema jurídico, la Constitución establece su estructura formal, de la que son consecuencia las relaciones entre sus fuentes del derecho y las relaciones de competencia entre los órganos constitucionales. De esta manera, también será interpretación posible cualquiera que se justifique en la estructura constitucional del sistema de competencias, debiendo inaplicarse la "voluntad del constituyente" o el "tenor literal del texto" cuando los resultados que presenten sean contrarios a la distribución constitucional de competencias (lo que en la interpretación constitucional se conoce como principio de corrección funcional).

Así, pues, tomados 1) el agotamiento interno de los criterios de interpretación; 2) la unidad del sistema jurídico; y 3 ) el sistema constitucional de competencias, como razones excluyentes que justifican la decisión de no aplicar la "voluntad del constituyente" ni el "tenor literal del texto", la cláusula de interpretación reconstruida dice: "El Tribunal Constitucional Plurinacional fundará sus decisiones en la voluntad del constituyente, según sus documen- 
tos, actas y resoluciones, o en el tenor literal del texto de la Constitución, salvo que no produzcan ningún resultado o que los resultados producidos sean contradictorios entre sí o con otras normas de la Constitución, o alteren el sistema de competencias por ella establecido, en cuyo caso las fundará en otros criterios".

Aunque por su ámbito de validez personal sólo el Tribunal Constitucional está jurídicamente vinculado por esta cláusula, los demás órganos constituidos también deben aplicarla. Su cumplimiento es una exigencia práctica. Ésta dicta que al aplicar la Constitución, los poderes públicos la interpreten según los criterios que usará el Tribunal para el enjuiciamiento de sus actos.

\section{EL CARÁCTER NORMATIVO DE LOS PRECEDENTES CONSTITUCIONALES: SU PREEMINENCIA SOBRE EL DERECHO ORDINARIO Y SUS EFECTOS VINCULANTES ${ }^{26}$}

La unidad del sistema jurídico exige que los precedentes constitucionales gocen de preeminencia sobre el derecho ordinario, pues su órgano productor es el único autorizado por el sistema para pronunciarse autoritativamente sobre la Constitución (art. 196). Esto es consecuencia de que el custodio de la Constitución sea un tribunal, vale decir, un órgano cuyas decisiones son jurídicamente incontrovertibles (art. 203) ${ }^{27}$. La naturaleza de sus decisiones es lo que hace del Tribunal Constitucional Plurinacional el supremo intérprete de la Constitución. De ahí que la supremacía normativa se predique de la Constitución tal como resulta interpretada por su custodio. En este sentido, en lo que respecta a las disposiciones constitucionales cuyo significado jurídico no ha variado con la reforma de la Constitución, los precedentes del Tribunal Constitucional mantienen su calidad de interpretación autoritativa de las mismas.

En los sistemas jurídicos de tradición civil, el papel del juez se considera más restringido y modesto que el papel que sus pares desempeñan en los sistemas jurídicos de derecho común (common law). La razón de esta diferencia está en el efecto vinculante que los precedentes judiciales tienen en los sistemas de derecho común, es decir, en la obligación que tienen los jueces de resolver casos similares conforme a sus propias decisiones, las decisiones de sus pares

26 Este punto está formulado en argumentos de teoría general del derecho, válidos para cualquier sistema jurídico positivo, por eso que se apoye en la unidad del sistema como tesis central. Para un análisis específicamente constitucional y lo suficientemente amplio sobre el efecto vinculante de los precedentes constitucionales en Bolivia, véase Jorge Asbun. Estudios constitucionales. Págs. 73-116. $1^{\mathrm{a}}$ edición. Santa Cruz. El País. (2008).

27 El artículo 203 ("Las decisiones y sentencias del Tribunal Constitucional Plurinacional son de carácter vinculante y de cumplimiento obligatorio y contra ellas no cabe recurso ordinario ulterior alguno") no se refiere al carácter vinculante general de los precedentes, sino a la obligatoriedad de la parte resolutiva de las sentencias (el fallo). 
o las de sus superiores (stare decisis); mientras que en la tradición civil el carácter normativo de los precedentes, más allá del caso en litigio, es resistido.

Esta resistencia se explica por 1) la influencia de la Revolución Francesa, que, en su afán de imponerse al antiguo régimen y de dotar de legitimación política al poder público, llevó la división de poderes al equívoco de asumir que sólo el cuerpo legislativo creaba derecho. Así se aseguraba de antemano que la judicatura acompañase el proceso revolucionario juridizado por la Asamblea Nacional ${ }^{28}$. 2) La ideología de la codificación, que, como producto del naturalismo racionalista de los siglos XVII y XVIII, creyó haber encontrado unas leyes universales llamadas a regir el comportamiento humano. Esto degeneró en la exageración de la importancia de los códigos, como si fueran los depositarios de todo el derecho. Y 3) el predominio de la Escuela de la Exégesis que, como consecuencia de los dos puntos anteriores, describió al juez como un puro aplicador mecánico de las leyes. Por un lado, no podía participar en el proceso de creación del derecho, porque esa labor le correspondía a la legislatura; y, por otro, la interpretación e integración del derecho, como fuentes tradicionales de su poder, ya no tenían razón de ser, dado que el alto grado de perfección supuestamente alcanzado en los códigos las hacía innecesarias.

Ninguna de estas razones es de derecho positivo. Y en el sistema de derecho vigente no hay norma que niegue a los precedentes judiciales su efecto vinculante. El punto de partida de esta afirmación es la unidad del sistema jurídico, que presupone la unidad de su norma fundacional. En este sentido, siempre que la norma fundacional de un sistema, además de establecer las formas de creación de nuevo derecho, tenga un contenido material -el que fuera-, el respeto al precedente será un elemento de dicho sistema, pues que los casos similares sean decididos de modo similar importa mantener tal unidad.

Hasta aquí la teoría del derecho; ahora su aplicación. Resulta que 1) la Constitución no sólo es una norma dotada de contenido, sino que 2) parte de ese contenido consiste en la igualdad de las personas ante la ley y en la garantía de seguridad jurídica ${ }^{29}$, lo que 3) significa que ante todos los hechos "A" el derecho debe ser "B" (se entiende que "A" supone la identidad fáctica del supuesto y sus circunstancias), por lo que, en consecuencia, 4) de la propia

28 De hecho, hasta tiempos prerrevolucionarios los jueces continentales actuaban de manera similar a sus colegas ingleses, desarrollando un cuerpo de normas de derecho común y su propia doctrina del precedente. Esto fue interrumpido por la Revolución, que reclamaba el monopolio en la producción jurídica para poder consolidar sus reformas por medio del derecho (cfr. John Henry Merryman. La tradición jurídica romano-canónica. Págs. 47-59, 72-80. $8^{\text {a }}$ reimpresión. México D.F. Fondo de Cultura Económica. (2003). Además, debe tenerse en cuenta que la separación conceptual entre creación y aplicación del derecho respondía a la necesidad ideológica de legitimación del poder público, pues la imagen de una autoridad creando derecho pero no derivando su poder directamente del pueblo soberano, rompía con el entendimiento primitivo de la división de poderes.

29 La exigencia de seguridad jurídica es ínsita a todo sistema jurídico, desde que ella supone la realización de su premisa conceptual formal por excelencia, a saber, el cumplimiento de sus normas. 
Constitución nace el respeto a los precedentes, en sus respectivas materias, del Tribunal Constitucional Plurinacional, del Tribunal Supremo de Justicia y del Tribunal Agroambiental, por cuanto 5) si ante los hechos "A" el derecho no fuera "B", sino indistintamente "C", "D" o "E", entonces no habría igualdad ante la ley ni tampoco habría garantía de seguridad jurídica ${ }^{30}$.

En contra del respeto al precedente se ha invocado la independencia judicial. Pero tal argumento olvida que si bien los tribunales no están sometidos a ningún otro poder, sí lo están a la Constitución, que es de donde emana el imperativo de unidad del sistema jurídico, y que conlleva el respeto al precedente.

Si por independencia judicial se quiere significar el derecho de los jueces a decidir según su propio razonamiento jurídico, debe recordarse es que el respeto al precedente no implica hacer del precedente algo de suyo inalterable, porque lo que ello conllevaría es la pretensión de estancar la historia y estancar el raciocinio jurídico. El respeto al precedente implica el imperativo jurídico de alterarlo sólo con base en la construcción de argumentos que justifiquen que su alteración acomoda mejor en el sistema jurídico, como canon general que se aplicará por igual a la totalidad de casos futuros que se presenten. De hecho, el argumento de autoridad, que consiste en la invocación de precedentes, está limitado por el derecho de los tribunales a cambiar el curso de su jurisprudencia.

Se entiende que el precedente no está constituido por el texto de la sentencia ni únicamente por su parte resolutiva, sino, con un criterio de razón suficiente, por el derecho declarado aplicable a las hipótesis necesarias para justificar la decisión. Por tanto, no hacen parte del precedente las cuestiones incidentales, como referencias doctrinales, citas de derecho comparado, mención a disposiciones jurídicas aplicables al asunto, pero no decisivas para su resolución, o los hechos que, aunque considerados, no son determinantes para justificar la decisión final; todo lo cual se conoce como dicta, que no importa jurisprudencia ${ }^{31}$.

30 En su jurisprudencia el Tribunal Constitucional no tiene esto claro. De hecho, funda la obligatoriedad de sus precedentes en su ley de organización (cfr. STC 1781/2004-RAC, 16 de noviembre).

31 Decía Goodhart que el precedente se encuentra "tomando los hechos considerados por el juez y su decisión en tanto que basada en ellos" (Arthur L. Goodhart. Determining the ratio decidendi of a case. p. 182. 40 Yale Law Journal. (1930). El Tribunal Constitucional induce a confusión con respecto al valor jurídico de sus precedentes. Define su jurisprudencia con una contradicción en los términos: "como la doctrina constitucional boliviana creada a través de la interpretación constitucional [con] fuerza vinculante". Esta es la contradicción: si es doctrina entonces no tiene fuerza vinculante, que es el valor jurídico que corresponde a los precedentes en tanto que normas jurídicas. Al parecer, el Tribunal confunde las normas jurídicas con el documento que las contiene y por ello que equiparase sus precedentes a la doctrina, cuando, en realidad, el precedente es una norma jurídica contenida en una sentencia, la misma que, además del precedente, acoge una variedad de razonamientos, hechos, disposiciones legales y citas que por no ser parte del precedente sólo pueden ser invocados en futuros casos a título de referencia y, precisamente, ante los tribunales la doctrina sólo tiene valor referencial, y no fuerza vinculante (STC 1781/2004-RAC, 
Así entendido, lejos de contraponerse a la independencia judicial, el respeto al precedente la reafirma. La precondición para que el órgano judicial sea verdaderamente inmune a las presiones, es que exista con la dignidad de un auténtico poder del Estado ante los ojos del ciudadano, y a ello contribuye el carácter vinculante de sus decisiones. En efecto, 1) la unidad de la jurisprudencia beneficia al ciudadano, por redundar en certeza y previsibilidad respecto de las decisiones de los poderes públicos, incluyendo las judiciales. Por esto, LLEWELLYN dice que "aun cuando los predecesores hubiesen sido malos, ignorantes, tontos o parcializados, la certeza de que sus sucesores seguirán sus precedentes da la base para que se pueda prever las acciones de los tribunales" ${ }^{32}$. 2) Las garantías del ciudadano penden del supuesto de que el poder frene al poder. Como esto supone la eficacia del derecho como sistema de seguridad, es preferible que la interpretación autoritativa de la Constitución y las leyes sea vinculante, a que no lo sea. De hecho, el decisor que basa sus acciones en normas está adelantando sus futuras decisiones, lo que satisface un principio general de consistencia, que hace a la necesidad misma de seguridad jurídica. Y 3) el tema también envuelve la cuestión de la unidad del sistema jurídico. Al conllevar la realización de sus premisas conceptuales mismas, la unidad redunda en la eficacia del sistema. Y la premisa por excelencia de cualquier sistema normativo, incluso de uno totalitario, es que la sola existencia de normas de aplicación cierta ya supone limitar la arbitrariedad.

\section{LAS FUENTES ORDINARIAS DEL DERECHO}

\section{LOS TRATADOS}

Como fuentes de derecho interno, interesan los tratados incorporados al ordenamiento a través de su ratificación (art. 257. I). En lo que se refiere a la posición de los tratados en el sistema jurídico, el texto expreso de la Constitución plantea una antinomia: por un lado dice que los tratados se aplican

16 de noviembre). El Tribunal Constitucional se refiere a la identidad de hipótesis de hecho de los precedentes (es decir, el elemento "A" en la fórmula si es "A" debe ser "B"), como "analogía fáctica", queriendo decir con ello que las hipótesis que fundan la decisión en un caso deben ser las mismas en otro, para que a éste se aplique el precedente sentado (cfr. AC 004/2005-ECA, 16 de febrero). No se debe, pues, confundir la analogía a la que hace mención el Tribunal con la analogía como procedimiento de integración del derecho ante la insuficiencia de legislación expresa, pues ésta importa el análisis de dos situaciones de hecho, a efectos de argumentar una semejanza suficiente como para que se justifique la aplicación, al caso no reglado, de la solución prevista expresamente por el ordenamiento para el caso reglado (cfr. STC 221/2004-RAC, 12 de febrero).

32 Karl Llewellyn. The Bramble Bush (reimpresión). p. 65. Nueva York, Oceana/Oxford University Press. (1961). 
con preferencia a las leyes ${ }^{33}$ (art. 410. II), pero, por otro lado, también dice que los tratados tienen rango de ley (art. 257. I). Una primera forma posible de eliminar la antinomia pasaría por interpretar que la Constitución establece tres regímenes jerárquicos para los tratados:

33 Sobre la posición de los tratados en el sistema de fuentes, la Asamblea Constituyente recibió esta propuesta: "Las normas de derecho internacional tienen jerarquía superior a las leyes" (la segunda parte de este artículo, que trata de las normas internacionales sobre derechos humanos, ha sido comentada en la nota al pie 15). Decía su fundamentación: "18. Descripción general. Este artículo regula las relaciones entre las normas de fuente internacional y las normas de fuente interna (desde luego sus efectos se limitan al derecho nacional). Su referente de derecho comparado es la Constitución de Argentina (art. 75.22). Por su materia es una norma relativa a la jerarquía del sistema de fuentes. 19. Justificación de la fórmula. Se estima que la fórmula del artículo propuesto es idónea y suficiente, porque en el contexto del articulado basta con la referencia a las normas de derecho internacional para entenderse aquellas que obligan al Estado. Asimismo, basta con la referencia a jerarquía superior a las leyes para que queden incluidas las ordinarias, orgánicas y estatutarias, que por igual son leyes. (...). 20. Relaciones entre fuentes (dualismo). El derecho es por definición un orden dinámico: un sistema que regula su propia creación y regula de manera formal las relaciones entre sus normas. Consecuencia de su carácter dinámico es que la estructura del sistema jurídico se organice jerárquicamente. No obstante su estructura, las relaciones formales entre las normas del sistema se rigen no sólo por el criterio central de jerarquía, sino también por otros criterios. Tales son los de competencia, prevalencia, especialidad y temporalidad. No cualquiera de estos criterios puede ser adoptado para regular las relaciones entre las normas de fuente internacional y las de fuente interna. Los derechos nacionales que cuentan con normas de integración dualistas atribuyen a los tratados el rango del acto legislativo que los transformó en derecho interno (rango de ley). Los inconvenientes de esta solución surgen al momento de resolver las antinomias entre normas provenientes de estas dos fuentes: puesto que no puede hacerse por aplicación del criterio de jerarquía, se lo debe hacer según el criterio de temporalidad, salvo cuando una de las normas en conflicto sea especial con relación a la otra. Así se llega a la posibilidad de que una ley posterior derogue un tratado anterior, con lo que ello implica en términos de comprometer la fe del Estado. A su vez, el rango de ley atribuido a los tratados extiende sus efectos a las normas de derecho internacional consuetudinario, puesto que, por un lado, la regla en la materia es que dichas normas se incorporan en los sistemas estatales desde su formación, y, por otro, lo hacen con la misma jerarquía en que los tratados son incorporados. 21. Jerarquía formal. Fundado en la primacía del derecho internacional, el artículo propuesto posiciona las normas de dicho orden en un estrato intermedio entre la Constitución y las leyes (incluyendo las de carácter orgánico o estatutario). La solución adoptada responde a un imperativo de coherencia que es connatural a todo sistema de derecho positivo, pues, a la vez que hace de las normas de derecho internacional fuente de validez de las leyes, reconduce la resolución de antinomias entre normas internas e internacionales a los controles de legalidad y de constitucionalidad. La opción por el criterio de jerarquía también puede explicarse por exclusión de los demás criterios. Así, el criterio de competencia ciertamente es el fundamental en la medida que resuelve las antinomias mediante la nulidad de las normas producidas sin competencia, pero requiere la previa delimitación de competencias entre dos o más fuentes, y tal no ocurre entre el derecho internacional y el interno. No hay asuntos que por su materia sean objeto de regulación sólo por el derecho internacional o sólo por el nacional; y si los hubiera, tendría que ser una norma de derecho internacional la llamada a establecerlos, pues es el orden que tiene primacía, ergo capacidad para distribuir materias entre las distintas fuentes. Pero tal norma no existe. (...). 22. Jerarquía formal de las normas de derecho internacional. En virtud de este artículo, no sólo los tratados, sino todas las normas de derecho internacional que forman parte del derecho nacional (véanse párrafos 15-17), tienen jerarquía superior a las leyes. Esto responde a una característica propia del derecho internacional, cual es la de que no exista una ordenación jerárquica del sistema de fuentes al modo de la existente en el derecho interno. (...). De ahí que entre sus normas no haya una clara jerarquía formal o positiva, y de ahí también que cuando pasan a formar parte del derecho interno lo hagan todas con la misma jerarquía" (HoRAcio Andaluz. Págs. 93-96. En ob. cit. en nota al pie 15). 
1) rango constitucional, para los tratados que integran el bloque de normas constitucionales. 2) Rango supralegal, para los tratados sobre las materias listadas en el artículo 257. II y para los de cualquier materia a los que, eventualmente, por solicitud del cinco por ciento de los ciudadanos registrados en el padrón electoral, se les aplique el procedimiento del artículo 259. I. La superioridad de estos tratados se fundaría en las mayores complejidades de su procedimiento de creación. Como para ellos se exige su aprobación por "referendo popular vinculante previo a [su] ratificación" (arts. 257. II y 259. I), al tener una forma más difícil, es aceptable al pensamiento jurídico que se les reconozca mayor jerarquía que a los tratados que siguen la ratificación legislativa ordinaria (art. 158. I. 14). Y 3) rango legal (art. 257. I), aplicable como criterio residual a todos los demás tratados. Éstos se relacionarían con las leyes por el criterio de temporalidad. Si fueran derogados por ellas, la regla pacta sunt servanda comprometería la consiguiente responsabilidad internacional del Estado, en la medida en que resultaran incumplidas sus obligaciones internacionales ${ }^{34}$.

El problema de esta construcción es que reduce el ámbito de aplicación material del artículo 410. II, haciendo que el rango supralegal sea aplicable sólo a los tratados para los que eventualmente se recurra al referendo popular y a los tratados sobre cuestiones limítrofes. Salvo éstos, todos los demás listados en el artículo 257. II versan sobre cuestiones de integración, vale decir, sobre materias de jerarquía constitucional, por tratarse de normas de derecho comunitario (bloque de constitucionalidad). En consecuencia, se habría formulado una excepción tan amplia como la regla expuesta en el artículo 410. II.

Otra forma posible de eliminar la antinomia es reconstruir los artículos 257. I y 410. II según el criterio de fuerza jurídica pasiva (capacidad de resistencia de una norma frente a otras). En esta interpretación, los tratados (todos menos los del bloque de constitucionalidad) tendrían jerarquía formal de ley (art. 257. I). Pero otras normas con el mismo rango no podrían derogarlos, en virtud de su aplicación preferente sobre ellas. Para esto, habría que asumir que tal preferencia se debe a su mayor fuerza jurídica pasiva: las otras normas del mismo rango serían incapaces de incidir en los tratados, porque al comportar su formación el concurso de voluntades de dos o más Estados, los tratados obedecen a un proceso de producción más complejo.

34 Que una ley derogue a un tratado no significa la terminación de éste, pues su terminación, así como su formación, es una cuestión de derecho internacional, no de derecho interno. Esta derogación sólo supone su inaplicabilidad en el ámbito interno y, por tanto, en la medida que su inaplicación suponga incumplimiento de sus términos, acarrea la responsabilidad internacional del Estado por el incumplimiento de los mismos, causado por un acto propio, a saber, la promulgación de la ley derogante del tratado. 
La ventaja de esta interpretación es que el criterio de temporalidad no se aplicaría a las relaciones entre los tratados y las demás normas con rango de ley, con beneficio del cumplimiento de las obligaciones internacionales. Además, el recurso al concepto de fuerza jurídica pasiva permite eliminar la antinomia entre los artículos en pugna sin desmedro de su ámbito de aplicación material.

\section{LAS LEYES NACIONALES, LOS ESTATUTOS AUTONÓMICOS, LAS CARTAS ORGÁNICAS Y EL RESTO DE LEGISLACIÓN DEPARTAMENTAL, MUNICIPAL E INDÍGENA}

El artículo 410. II. 3 de la Constitución presenta en el mismo nivel estructural del sistema jurídico a "las leyes nacionales, los estatutos autonómicos, las cartas orgánicas y el resto de legislación departamental, municipal e indígena", "de acuerdo a las competencias de las entidades territoriales" (art. 410. II). Esta descripción es suficiente con respecto a las relaciones formales entre leyes nacionales, estatutos autonómicos y cartas orgánicas. Pero no lo es con respecto a las relaciones de las leyes entre sí, ni a las del resto de la legislación departamental, municipal e indígena con referencia a los estatutos autonómicos, cartas orgánicas y leyes nacionales.

Lo cierto es que las relaciones formales entre estas fuentes producen una estructura de tres niveles jerárquicos: 1) por su fuerza jurídica, las leyes que deben ser aprobadas por dos tercios de votos son superiores a las leyes ordinarias y a los estatutos autonómicos y las cartas orgánicas; 2 ) en un nivel intermedio están las leyes para cuya aprobación basta la mayoría absoluta, los estatutos autonómicos y las cartas orgánicas, cuyas relaciones mutuas se rigen por la competencia constitucional atribuida a sus respectivos órganos productores; y 3) las demás normas departamentales, municipales e indígenas están subordinadas a sus respectivos estatutos autonómicos y cartas orgánicas, en la medida en que constituyen las normas supremas de los subsistemas descentralizados y autonómicos, y en consecuencia, las fuentes que les proveen de validez ${ }^{35}$.

35 Un sistema jurídico puede estar compuesto por distintos subsistemas. Esto es lo que ocurre con los subsistemas estaduales en relación con el sistema federal, con los subsistemas autónomos y descentralizados en relación con el sistema nacional, o con los subsistemas nacionales con relación a los sistemas supranacionales de integración o a las normas de derecho internacional. Esta pluralidad de subsistemas forma una unidad sistémica cuando la validez de sus respectivas normas fundacionales es reconducible a una única norma, porque en términos de unidad la pluralidad de subsistemas sólo es cognoscible desde una perspectiva monista. Esto es, a partir del "requerimiento epistemológico de que todo el derecho sea considerado en un solo sistema", porque el conocimiento jurídico tiene la tarea de presentar su objeto de estudio (el material jurídico) como una unidad. (HANS KelSEN. Introduction to the problems of legal theory. ( $1^{\mathrm{a}}$ reimpresión). pág. 111. Nueva York. Clarendon Press. (2002). En términos de ciencia jurídica, así es como conceptualmente debe leerse 
En cuanto al primer nivel, el procedimiento de formación de las leyes exige que sean aprobadas por mayoría absoluta (art. 163), excepto las que deben aprobarse por dos tercios. Integran esta excepción las leyes expresas levantando la prohibición de asentamiento de extranjeros en la zona de seguridad fronteriza $^{36}$ (art. 262. I), la Ley Marco de Autonomías y Descentralización (art. 271. II) y la Ley de Reforma Constitucional (art. 411. II). La última no será tratada aquí, pues no es una fuente por sí misma, sino parte de un procedimiento para la reforma parcial de la Constitución como fuente del sistema jurídico.

Pues bien, 1) en su relación con las leyes aprobadas por mayoría absoluta (leyes ordinarias), las leyes aprobadas por dos tercios tienen mayor fuerza jurídica, la misma que deriva de la mayor complejidad que la Constitución exige para su producción. Por tanto, el criterio de temporalidad no se aplique a sus relaciones con las leyes ordinarias. 2) El efecto de la mayor fuerza jurídica alcanza sólo a las materias para las que la Constitución exige aprobación por dos tercios. De manera que inclusive dentro de la misma ley (expresa o marco) puede haber disposiciones que, votadas por dos tercios, no tengan mayor fuerza que las leyes ordinarias, si no constituyen materia que debe ser legislada por dos tercios. 3) El hecho que la Constitución delimite el ámbito de legislación propio de cada ley aprobada por dos tercios (arts. 262. I y 271. I), supone la unidad de materia en su tratamiento. Así, la ley expresa del artículo 262. I no puede legislar materias de la Ley Marco del artículo 271. II, y viceversa, porque violarían las disposiciones constitucionales que delimitan el ámbito de legislación propio de cada forma. Deriva de esto de que entre ambas no se aplica el criterio de temporalidad. 4) Una ley ordinaria que legislase materias sujetas al procedimiento de dos tercios sería inconstitucional, por violar las disposiciones de reserva de tal procedimiento (arts. 262. I y 271). 5) La relación de la ley expresa del artículo 262. I con los estatutos autonómicos y las cartas orgánicas se define por la competencia material de sus órganos productores y la unidad de materia en su tratamiento. Así, sin importar su mayor jerarquía, por la ley expresa la Asamblea Legislativa Plurinacional no puede legislar lo que es materia de los órganos deliberativos territoriales (art. 275). Y 6) en su relación con los estatutos autonómicos y las cartas orgánicas, la Ley Marco condiciona su validez, en la medida en que regula el procedimiento para su formación y operatividad (art. 271. I). Pero su capacidad normativa está limitada por la competencia material que la Constitución atribuye a las entidades territoriales descentralizadas y autónomas.

Con respecto a las leyes que requieren votación calificada, habría sido útil incorporar al sistema jurídico boliviano las leyes orgánicas y estatutarias,

el pluralismo jurídico al que se refiere la Constitución (art. $1^{\circ}$ ).

36 Esta prohibición ingresó a la Constitución en las reformas de 1938, aunque apenas ahora se exige una votación calificada para su levantamiento. 
ya que, por su propia materia (las primeras referidas a la organización de los poderes públicos ${ }^{37}$ y las segundas a los códigos), estas leyes debieran ser invulnerables a las modificaciones incidentales del legislador ordinario ${ }^{38}$.

Con respecto a las leyes ordinarias, los estatutos autonómicos y las cartas orgánicas (nivel intermedio), la relación entre estas formas normativas se define por la competencia material atribuida por la Constitución a sus respectivos órganos productores, con lo que carece de relevancia el criterio de temporalidad. Por tanto, el acto normativo producido por fuente incompetente será inconstitucional por violar la distribución constitucional de materias entre los distintos órganos legislativos. De manera que, siendo cierto que sólo las leyes rigen para todo el territorio nacional (art. 145), también lo es que sólo son válidas si legislan materias de competencia de la Asamblea Legislativa Plurinacional. En este sentido, la organización institucional de las entidades territoriales descentralizadas y autónomas queda excluida del ámbito de las leyes, por cuanto es la Constitución la que dispone que tal competencia normativa corresponda a los órganos deliberativos de las entidades territoriales (art. 275). Del mismo modo, los estatutos autonómicos y las cartas orgánicas no son fuentes competentes para legislar sobre las materias listadas en el artículo 298. I de la Constitución, porque son competencias privativas del nivel central de gobierno, por tanto, materia de ley.

En cuanto al "resto de la legislación departamental, municipal e indígena", 1) tal legislación no está al mismo nivel que sus respectivos estatutos autonómicos y cartas orgánicas. Estos instrumentos son las normas supremas de los distintos subsistemas normativos descentralizados y autónomos, por lo que las normas que producen los órganos de dichos subsistemas le son inferiores, ya que de ellos derivan su validez. 2) Por pertenecer a subsistemas normativos distintos (el "resto de la legislación departamental, municipal e indígena" pertenece a los subsistemas descentralizados y autónomos, y las leyes al subsistema central), entre la legislación descentralizada y autónoma y la legislación central no se producen relaciones formales de jerarquía, temporalidad ni especialidad. 3) La "legislación departamental, municipal e indígena" es fruto de las respectivas competencias que constitucionalmente han sido atribuidas a sus órganos productores. Por tanto, en caso de conflicto, éste se resuelve con la inconstitucionalidad del acto ultra vires, sea que el vicio se sustancie como un conflicto de competencias entre los órganos productores

37 En el derecho comparado no es extraño encontrar que se asigne la forma de ley orgánica a materias distintas a la organización de los poderes públicos. En estos casos la denominación es impropia.

38 Las leyes que en Bolivia reciben la denominación de orgánicas, como en su momento la antigua Ley Orgánica de Municipalidades (L. 696, ene. 10/85) o actualmente la Ley Orgánica del Ministerio Público (L. 2175, feb. 13/2001), sólo dan cuenta de su objeto de regulación (un órgano público), pero no dicen nada con respecto a su fuerza jurídica, pues todas ellas son por igual leyes ordinarias, con lo que lo de "orgánicas" termina siendo un puro nombre, pero no un efecto jurídico atribuido por la Constitución a una forma específica de fuente legislativa. 
(art. 202.3) o como un conflicto normativo por violación de la distribución constitucional de competencias (art. 202.1). Y 4) la legislación departamental, municipal e indígena de cada uno de los distintos subsistemas descentralizados y autónomos, se aplica en sus respectivos ámbitos territoriales, por lo que es un imposible lógico-normativo que entre normas de subsistemas distintos se produzcan antinomias.

\section{EL DERECHO CONSUETUDINARIO: EL DERECHO INDÍGENA ORIGINARIO CAMPESINO}

La Constitución dice que el derecho indígena originario campesino es un "vínculo particular de las personas que son miembros de la respectiva nación o pueblo indígena originario campesino" (art. 191. I). Este derecho es de fuente consuetudinaria. El "vínculo particular" es la convicción de obligatoriedad jurídica (opinio iuris) que acompaña a determinada práctica (consuetudo), haciendo que la conducta contraria se considere ilícita. Para la Constitución, una nación o pueblo indígena originario campesino es "toda colectividad humana que comparta identidad cultural, idioma, tradición histórica, instituciones, territorialidad y cosmovisión, cuya existencia es anterior a la invasión colonial española" (art. 30. I). Por tanto, como fuente de producción normativa, la costumbre es una forma jurídica limitada espacialmente al territorio de estas colectividades, que es el de sus respectivas autonomías indígenas. Siendo este su ámbito espacial de validez, la capacidad de producción jurídica de las autonomías indígenas deriva de la distribución constitucional de competencias entre los distintos subsistemas normativos (centrales, autónomos y descentralizados). En consecuencia, la regulación consuetudinaria únicamente puede tener por objeto las materias atribuidas a los subsistemas indígenas originarios campesinos en sus respectivos estatutos autonómicos. Que la existencia de estas naciones o pueblos sea "anterior a la invasión colonial española" no impide que su derecho se subordine al derecho de la Constitución, porque en un sistema jurídico la anterioridad históricocronológica (la existencia prerrepublicana) no es igual a la anterioridad lógico-normativa (la supremacía de la Constitución) ${ }^{39}$.

39 No debe confundirse la realidad histórica con la realidad normativa. Si se trata de la distribución de competencias entre distintos subsistemas, el dato determinante son las normas que hacen tal distribución, las mismas que sólo pueden ser superiores a los subsistemas. De lo contrario, no podría darse unidad al sistema jurídico. Piénsese, por ejemplo, en el hecho que Connecticut fue la primera colonia inglesa en América en tener una Constitución ("Fundamental orders"), que data de 1639. Pero, al formar parte de la federación estadounidense, la anterioridad histórica de su constitución quedó sometida a la anterioridad normativa de la Constitución federal, promulgada más de un siglo después (1787). Lo mismo con respecto a los cantones suizos, donde la existencia independiente de algunos de ellos va tan atrás como hasta 1291, cuando suscribieron una "Carta de la Alianza" para luchar contra el Sacro Imperio Romano Germánico. Entrada en vigor la Constitución federal suiza de 1848 , la anterioridad histórica de los sistemas cantonales se sometió a la anterioridad normativa 
En el derecho interno la costumbre como forma de producción del derecho decayó a la par que el Estado moderno se consolidaba. Éste se construyó a partir de la noción de soberanía, entendida como poder absoluto y perpetuo y cuyo ejercicio se traduce en la facultad de dictar leyes, contra las que no pueden primar las leyes de otros Estados ni las costumbres de sus súbditos ${ }^{40}$.

de la norma que los unifica, convirtiéndose en subsistemas del sistema federal. Lo mismo ha ocurrido en el proceso de unificación de los países europeos tal como hoy los conocemos. Y lo mismo es lo que ha venido ocurriendo con el progresivo proceso de centralización de la Unión Europea. En la medida que más se centraliza, más condiciona los sistemas de sus Estados miembros, con mucho que sus miembros preexistan a la Unión. De estos ejemplos, el punto que queda es este: cuando sistemas jurídicos preexistentes (anterioridad histórico-cronológica) pasan a formar parte de un sistema mayor, su validez se subordina a las normas de éste (anterioridad lógico-normativa), lo mismo que la norma anterior se subordina a la norma posterior superior (como el Código Civil de 1975 lo hace con respecto a la Constitución del 2009).

40 La soberanía es un concepto histórico: "El concepto de soberanía es tan reciente como el Estado moderno. De hecho, aparece a causa de las circunstancias contra las que el Estado moderno en germinación debió enfrentarse para llegar a constituirse como tal. En sus orígenes, el Estado moderno fue atacado simultánea y constantemente por dos flancos: desde arriba por la Iglesia y el Imperio Romano, y desde abajo por los señores feudales y las corporaciones. Mientras que la Iglesia quería poner al Estado a su servicio y someterlo a su poder, el Imperio Romano pretendía no reconocerle valor superior al que había reconocido a sus provincias desde las épocas de la Lex Julia municipalis. Por su parte, los señores feudales y las corporaciones se concebían como poderes independientes y enfrentados al Estado. De hecho, el pueblo estaba sometido primero a los barones y sólo indirectamente al rey. En el sistema feudal el pueblo prestaba fidelidad a sus señores, los barones, y cuando necesitaban acudir en justicia, acudían a los tribunales de sus señores. Los señores feudales tenían, en efecto, razones suficientes para considerarse enfrentados al Estado, puesto que sus poderes y derechos de carácter público eran los que corresponderían al Estado que terminaría por imponerse, reclamando para sí los poderes de imperium ejercidos por los señores. Es en medio de estas circunstancias cuando surge el concepto de soberanía. En el mundo antiguo no había nada que se opusiera al poder del Estado como los poderes que se opusieron al Estado moderno. Por ello que entonces no hubiera necesidad de un concepto como el de soberanía. En el caso de Roma, no había motivo para comparar el poder del Estado romano con un poder superior, igual o siquiera próximo al suyo. Por eso los romanos no se vieran impelidos a elaborar el concepto de soberanía. Las expresiones maiestas, potestas e imperium decían de la potencia y la fuerza del pueblo romano, su poder civil y militar, pero no indicaban nada del contenido y las limitaciones del Estado ni de la independencia de Roma con respecto de los poderes extranjeros. El concepto de soberanía se debe a particulares circunstancias históricas. La soberanía es, pues, una categoría histórica (JELLINEK). Aun durante la Edad Media la doctrina oficial dominante consideraba a todos los Estados cristianos como subordinados de derecho al Imperio Romano. Pero esta doctrina tuvo que adaptarse. El derecho a la independencia de los príncipes y las ciudades, como ocurrió con Florencia y Pisa, tuvo una marcada influencia privatista, propia de la época. El emperador concedía la independencia en virtud de la prescripción por posesión inmemorial. La independencia no se consideraba como propia de la naturaleza del Estado, sino como consecuencia de un título jurídico revocable. Pero la idea de soberanía no es fruto de esta doctrina oficial ni de los esfuerzos del Imperio por adecuarse a los nuevos tiempos sin perder su poder imperial. El concepto de soberanía es propiamente francés. Es Francia la que le da su carácter absoluto. Pero no debe olvidarse que la soberanía es una categoría histórica y que, como tal, debe entendérsela conforme a las circunstancias que provocaron su nacimiento. El Estado moderno debía afirmarse como poder absoluto, y eso significaba que debía liberarse del poder de la Iglesia y del Imperio Romano, y someter bajo su autoridad a los señores feudales y las corporaciones. Entendido en su momento histórico, el poder absoluto del Estado es un poder relativo. Desconoce la autoridad de cualquier poder político distinto del suyo, pero no niega su existencia. Los reclamos son por la independencia, y es eso lo que quiere decir "poder absoluto libre de toda ley sobre ciudadanos y súbditos" (BodiN). Por eso la solución clásica al problema de la soberanía tiene el mérito de ser una solución histórica. Presenta la soberanía con el 
De esta manera, el monopolio estatal de la producción jurídica es resultado del proceso histórico de consolidación del Estado moderno. De ahí que, desde sus albores, los teóricos del Estado moderno, en el entendimiento de que la unidad política no era alcanzable al margen de la unidad jurídica, concibieron para la costumbre un papel enteramente secundario, asignando la primacía al derecho de fuente estata ${ }^{41}$. Así se explica que la costumbre haya perdido protagonismo como fuente de producción normativa, y así se llega a que en el derecho nacional las relaciones entre fuentes se resuelvan por la primacía del derecho de fuente estatal, importando la costumbre sólo en tanto el derecho del Estado la confirme o remita a ella (costumbre secundum legem $)^{42}$ o en tanto regule cuestiones no contempladas en la ley (costumbre praeter legem), en cuyo caso su existencia se funda en su propia eficacia y su aplicación subsidiaria se justifica en la integridad del sistema jurídico.

En el caso del derecho indígena originario campesino, se trata de una costumbre secundum legem: existe como fuente productora de derecho en los distintos subsistemas normativos autónomos indígenas originarios campesinos en la medida que la Constitución remite a él (arts. 30. II. 14, 190. I y 191. I). Por tanto, es válido siempre que no sea contrario a los derechos y garantías constitucionales (art. 190. II) y se desarrolle dentro de las competencias atribuidas por la Constitución a estos subsistemas (art. 304). En consecuencia,

sentido que quiso imprimirle al erigirla en concepto político. La presenta tal y cual fue su origen en el siglo Xvi: la absoluta independencia del Estado con respecto de los poderes extranjeros -Iglesia e Imperio Romano- y su absoluta superioridad con respecto de sus súbditos -señores feudales y corporaciones. La soberanía es, por tanto, un concepto negativo, pues no expresa lo que es, sino lo que no es: no es dependencia ni es sumisión" (Horacio Andaluz. Positivismo normativo y derecho internacional. $1^{a}$ edición. Págs. 52-54. La Paz. Plural. (2005).

41 Para los teóricos absolutistas, la costumbre "sólo tiene fuerza por tolerancia y en tanto que place al príncipe soberano, quien puede convertirla en ley mediante su homologación. En consecuencia, toda la fuerza de las leyes civiles y costumbres reside en el poder del príncipe soberano". "La ley puede anular las costumbres, pero la costumbre no puede derogar la ley" (JEAN Bodin. Los seis libros de la república. $1^{\text {a }}$ edición. Págs. 46, 66 y 67. Madrid. Centro de Estudios Constitucionales. (1992)). En el mismo sentido: "cuando el uso prolongado obtiene la autoridad de una ley, no es la extensión del tiempo lo que determina su autoridad, sino la voluntad del soberano expresada mediante su silencio" (Thомаs Hoвbes. Leviathan. $1^{a}$ edición. Pág. 348. Nueva York. Penguin. (1968)). El triunfo de las revoluciones liberales no cambió la visión respecto de la costumbre: las tesis liberales coinciden con las absolutistas en la defensa del monopolio legal de la producción jurídica, porque, por un lado, la ilustración ve en la costumbre los prejuicios e ignorancia de los siglos anteriores que deben ser barridos por la razón, cuya expresión es la ley, y por otro lado, la ley permite certeza y regulación uniforme, contra la inseguridad sobre el conocimiento del derecho vigente que acarrea la costumbre y la desigualdad en las relaciones jurídicas que produce, fruto de ser una técnica de regulación descentralizada aplicada en sociedades fragmentadas (estamentos, gremios).

42 A manera de ejemplo, los casos en los que el derecho de fuente estatal confirma o reenvía a la costumbre son aquellos en los que expresamente se establece la vigencia de la costumbre en una cierta relación jurídica. Estos casos se identifican por el uso de expresiones como las siguientes: "cuando los usos lo autorizan" (C.C., art. 460), "según los usos" (C.C., art. 520), o "sujetándose a los usos" (C.C., art. 1142). También puede ocurrir que el derecho legislado utilice expresiones que remiten a prácticas sociales tales como "comportarse como un buen padre de familia". 
es una fuente subordinada a la Constitución y cuya existencia es válida en los términos normados por ella.

En este sentido, la Constitución se ha apegado a la naturaleza jurídica de la costumbre, reglando en consecuencia. Por ello que disponga que el derecho indígena originario campesino sea de base personal (art. 191. II. 1). Al ser la costumbre una técnica de producción normativa descentralizada, su ámbito de aplicación no puede ser más que personal, desde que la práctica consuetudinaria no obliga a quienes no han participado en su formación. Así, lo que la Constitución llama vigencia territorial es el ámbito espacial de aplicación de la costumbre a los miembros de una nación o un pueblo indígena originario campesino (base personal). Ese espacio es el territorio autonómico en que sus autoridades tradicionales están habilitadas por la Constitución para ejercer funciones jurisdiccionales, conforme al artículo 191. II. 3 ("esta jurisdicción se aplica" "dentro de la jurisdicción de un pueblo indígena originario campesino").

En lo que respecta a las relaciones del derecho indígena originario campesino con las normas de fuente formal, éstas son 1) de subordinación a la Constitución, a los respectivos estatutos de autonomías indígenas (lo que conlleva subordinación a la Ley Marco de Autonomías y Descentralización) y a la Ley de Deslinde Jurisdiccional. En este sentido, el derecho de las naciones o pueblos indígenas originarios campesinos a regirse por su propias normas de acuerdo con su cosmovisión (art. 30. II. 14), se circunscribe a las materias atribuidas a las autonomías indígenas (art. 304), dentro del marco del respeto a los derechos y garantías constitucionales (art. 190. II). Y 2) con relación a las fuentes formales de los otros subsistemas normativos, no se aplican los criterios de jerarquía, temporalidad ni especialidad, por cuanto la costumbre pertenece a un subsistema normativo autónomo. De esta manera, su relación con las demás fuentes pasa por la competencia constitucional de este subsistema, haciendo que la costumbre rija respecto de los miembros de los pueblos indígenas originarios campesinos en sus respectivos territorios y dentro del ámbito material de aplicación de sus respectivos estatutos autonómicos.

Lo dicho significa 1) que las decisiones de la jurisdicción indígena originaria campesina son recurribles en la jurisdicción constitucional, en la medida que sean violatorias de los derechos garantizados por la Constitución, porque éstos son el límite a la obligación de "toda autoridad pública o persona [de acatar] las decisiones de la jurisdicción indígena originaria campesina” (art. 192. I); 2) que el ejercicio de la jurisdicción indígena originaria campesina puede ser contestado por las jurisdicciones ordinaria y agroambiental, en cuyo caso es el Tribunal Constitucional Plurinacional el que decide el asunto (art. 202.11); y 3) que si lo que está en controversia es la efectiva existencia de una determinada práctica consuetudinaria (precondición para el ejercicio de la 
jurisdicción), la misma deberá probarse ${ }^{43}$, pues, por su propia naturaleza, la regla iura novit curia no corre con respecto a la costumbre.

\section{LOS DECRETOS, REGLAMENTOS Y DEMÁS RESOLUCIONES EMANADAS DE LOS ÓRGANOS EJECUTIVOS CORRESPONDIENTES}

El artículo 410. II. 4 de la Constitución se refiere a la vez a las normas (decretos, resoluciones) producidas por los órganos ejecutivos (centrales y descentralizados o autónomos), y al ejercicio de la potestad reglamentaria (reglamentos) que les corresponde. Este artículo debe leerse según la competencia material de los distintos órganos productores, por ser el criterio utilizado por la Constitución para estructurar las fuentes a este nivel. Así, las relaciones entre normas de fuente central y de fuente descentralizada y autónoma no se rigen por los criterios de jerarquía, temporalidad ni especialidad (inaplicables entre normas de distintos subsistemas), sino por el criterio de competencia. Esto implica la invalidez del acto normativo producido por un órgano fuera de su marco competencial.

Con relación al órgano ejecutivo central, desde 1826 el texto de la Constitución definió la potestad reglamentaria por referencia a la potestad ejecutiva ${ }^{44}$. Esto hizo que desde su redacción, como regla general, la competencia formal del órgano ejecutivo para producir derecho requiriese de habilitación legislativa previa. La excepción estaba dada por el cumplimiento de competencias normativas directamente atribuidas por la Constitución. Hoy la Constitución ha roto con esa redacción, presentando tal competencia en un texto separado, que lacónicamente dice que el órgano ejecutivo produce derecho en la forma

43 Al estar formada por hechos, las reglas consuetudinarias son objeto de prueba, pues de otro modo no puede verificarse su existencia más allá del alegato de la parte que la invoca. Así es en el derecho internacional, en que la carencia de órganos productores centralizados hace que la costumbre tenga el protagonismo que otrora lo tuvo en el derecho interno: "[en] las reglas consuetudinarias la existencia de la opinio iuris de los Estados se prueba por vía de inducción, tomando como punto de partida el análisis de una práctica suficientemente amplia y convincente, y no por vía de deducción a partir de ideas concebidas a priori" (Delimitación de la frontera marítima en la región del Golfo de Maine, Canadá/Estados Unidos, ICJ Reports-CIJ Recueil, 1984, p. 284). También los derechos estatales exigen la prueba de la costumbre. Dice el Código Civil de España: "La costumbre sólo regirá en defecto de ley aplicable, siempre que no sea contraria a la moral o al orden público y que resulte probada" (art. 1.3).

44 Decía el texto de 1826: "[es atribución del presidente de la República autorizar los reglamentos y órdenes para el mejor cumplimiento de la Constitución, las leyes y los tratados públicos" (art. 83.5). El texto vigente hasta el 2009 decía: "[es atribución del presidente de la República ejecutar y hacer cumplir las leyes, expidiendo los decretos y órdenes convenientes, sin definir privativamente derechos, alterar los definidos por ley ni contrariar sus disposiciones, guardando las restricciones consignadas en esta Constitución" (art. 96.1). Con el lenguaje propio de la dogmática de la época, el texto de 1861 definía muy bien el objeto de la potestad reglamentaria: "[es atribución del Poder Ejecutivo] expedir las instrucciones y reglamentos que sean necesarios para la ejecución de las leyes, cuidando de no alterar su espíritu con excepciones reglamentarias" (art. 54.2). 
de decretos supremos y resoluciones (art. 172.8). El hecho es que aunque la redacción ha cambiado, la norma no lo ha hecho: para el ejercicio de sus poderes normativos, el órgano ejecutivo necesita de habilitación legislativa previa, salvo la excepción dicha.

En un Estado de derecho la actuación de los poderes públicos es lícita cuando va precedida de una norma habilitante de competencia. Así, el sometimiento a la Constitución significa que los poderes públicos actúan sólo en virtud de competencias expresas o de poderes implícitos. Poderes implícitos son los ejercidos como medios constitucionalmente lícitos para el cumplimiento de competencias expresas. Tanto competencias expresas como poderes implícitos están limitados por la reserva de competencias a favor de otros órganos del poder público y por la prohibición de alterar los principios, derechos y garantías constitucionales ${ }^{45}$.

Llevado esto a la competencia normativa del órgano ejecutivo, resulta que la Constitución no ha alterado la herencia republicana en la materia,

45 Limitarse a afirmar que el principio de legalidad se satisface con la actuación conforme al derecho por parte de los órganos públicos es redundante y peligroso para la libertad democrática: redundante porque la prohibición de actuación contraria a normas es consecuencia de la propia existencia de éstas, por lo que la prohibición de actuación antijurídica es esencial a la existencia de un sistema de derecho; y peligroso para la libertad democrática porque puede prestarse a una lectura abusiva de la cláusula general excluyente (todo lo que no está jurídicamente prohibido está jurídicamente permitido, artículo 14. IV de la Constitución), que extienda impropiamente su ámbito de validez personal a los poderes públicos, pasando por alto, primero, que la cláusula está inserta en el título correspondiente a las garantías de la persona, lo que siembra la presunción a favor de su aplicabilidad a la persona y no a los poderes públicos y, segundo, que aun cuando no estuviese inserta en dicho título, el resultado sería el mismo (aplicable a la persona y no a los poderes públicos), por cuanto lo contrario supondría hacer de la Constitución una norma superflua, ya que el objeto de la Constitución no es dejar en la orfandad al ciudadano administrado ante los poderes públicos de los que él mismo es fuente, sino instituir un gobierno limitado por el derecho, lo cual sería una meta de suyo imposible si al Estado le estaría permitido todo lo que no está prohibido. Por eso el énfasis en las competencias expresas: "la autoridad administrativa no solamente debe abstenerse de actuar contra legem, sino que además está obligada a actuar solamente secundum legem, o sea en virtud de habilitaciones legales", (Raymond Carré de Malberg. Teoría general del Estado. (reimpresión). Pág. 449. México D.F. Fondo de Cultura Económica. (2000)). Respecto a los poderes implícitos, un buen antecedente de derecho comparado es la sentencia de Marshall en McCulloch c. Maryland (1819): "déjese que el fin sea legítimo, que esté dentro del ámbito de la Constitución, y todos los medios que le sean apropiados, que se adecuen plenamente a ese fin y que no estén prohibidos, sino que coincidan con la letra y espíritu de la Constitución, son constitucionales" (17 U.S., 4 Wheat, 316). En el derecho internacional la doctrina de los poderes implícitos también ha sido reconocida judicialmente en el asunto Reparación por daños sufridos al servicio de las Naciones Unidas (ICJ Reports-CIJ Recueil, 1949), al declararse el derecho de las Naciones Unidas a reclamar la reparación por la muerte de su mediador en la guerra árabe-israelí de 1948, Bernadotte. En el derecho boliviano el Tribunal Constitucional dijo que la competencia era conferida expresa o en "forma razonablemente implícita" por la Constitución y las leyes (STC 054/01-RDN, 16 de julio), donde lo reprochable es que no definir lo "razonablemente implícito" puede leerse como invitación al abuso de las competencias expresas, por ello que en el texto principal se haya querido recordar que si hay poderes implícitos los mismos 1) se conciben como medios constitucionalmente válidos (lícitos) para el cumplimiento de competencias expresas; y 2) están limitados por la reserva material de competencias a favor de otros órganos del poder público y por la prohibición de alterar los principios, derechos y garantías constitucionales. 
pues innovar en este campo habría supuesto distribuir las materias que van a legislarse entre el órgano ejecutivo y el órgano legislativo, lo que ciertamente no ha ocurrido. De manera que en el orden constitucional vigente la ley sigue gozando de una reserva formal que, por su posición jerárquica en correlato con la naturaleza y la finalidad del órgano que la genera y la legitimidad que su conformación traduce, hace que sólo la ley pueda regular todo lo que la Constitución no ha atribuido a otros órganos ${ }^{46}$. De ahí que el órgano ejecutivo no tenga poderes legislativos generales, y que por atribución directa de la Constitución su competencia para producir derecho le venga constitucionalmente limitada a determinados actos administrativos individualizados (designaciones y nombramientos, etc.) o al dictado de ciertas normas generales cuya materia está fuertemente regulada por la Constitución, como el estado de excepción (art. 172.26).

La necesidad de habilitación legislativa previa se justifica en la carencia de poderes legislativos generales que tiene el órgano ejecutivo. De ahí que, si no tiene poderes normativos por mandato de la Constitución, sólo puede tenerlos por mandato de una fuente superior a las fuentes que él produce. En términos generales, esa fuente es la ley. La superioridad de las leyes sobre las normas del órgano ejecutivo se funda 1) en la mayor complejidad de su proceso de producción, lo que dota a las leyes de fuerza jurídica superior a los decretos y las resoluciones del órgano ejecutivo (razón de teoría jurídica) y 2) en la mayor legitimidad democrática de su órgano productor (razón de teoría política). De esta manera, la habilitación es expresa cuando las leyes disponen que deba reglamentarlas, e implícita cuando, no habiendo tal mandato reglamentario expreso, el ejecutivo necesite reglamentarlas para su mejor cumplimiento (art. 172.1). En este último caso, la reglamentación es el medio constitucionalmente válido (poder implícito) para el ejercicio de la potestad ejecutiva (competencia expresa). Fuera de los casos dichos, adelantarse a la

46 La idea de reserva formal ("la ley lo puede todo", dentro del límite dicho) pareciera hacer irrelevante el principio de reserva legal, que supone que una materia sólo pueda ser regulada por ley formal, que es el caso, por ejemplo, de los derechos y garantías constitucionales (art. 109. II) y de los impuestos nacionales (art. 158.23). Pero eso no es cierto, por cuanto en la organización estatal de legitimidad democrática el objeto del principio de reserva legal consiste en imponer al legislador el deber de regular por sí mismo una materia determinada, lo que conlleva limitar su capacidad para dejar a la potestad reglamentaria la regulación de la materia objeto de reserva (potestas delegata non potest delegari: porque la delegación violaría la norma de competencia que estableció la reserva). En cambio, en la organización estatal de legitimidad monárquica, que es donde apareció la formulación original del principio, la reserva de ley suponía limitar la capacidad normativa general del órgano ejecutivo, excluyendo de su competencia determinadas materias, pues como se asumía que el poder del monarca era un derecho propio por su carácter originario (anterior a la constitución), entonces a él le correspondían todas las competencias que la constitución no le había privado (una norma general excluyente a su favor), de ahí que surgiese la técnica de las reservas, como medio para evitar que la regulación de determinados asuntos de directo interés para los súbditos quedase a las anchas del monarca, tales como la propiedad y la libertad. 
ley supondría que el órgano ejecutivo se atribuyese los poderes legislativos generales de los que carece ${ }^{47}$.

En cuanto a los órganos ejecutivos de las entidades territoriales descentralizadas y autónomas, es aplicable, mutatis mutandis, lo dicho para el órgano central. Esto supone la inferioridad jurídica de sus normas con respecto a las producidas por sus respectivos órganos legislativos, los mismos que carecen de competencia legislativa general, salvo que la norma suprema de los subsistemas descentralizados y autónomos disponga lo contrario.

Por último, cuando el artículo 410. II. 4 se refiere a las "demás resoluciones emanadas de los órganos ejecutivos correspondientes", se está refiriendo al resto de normas producidas por estos órganos, cuya regulación la hace el derecho ordinario. En cuanto al órgano ejecutivo central, tradicionalmente las "demás resoluciones" se han estructurado en forma jerárquica, atribuyendo mayor fuerza jurídica a las formas de más difícil producción. Así prima, por ejemplo, la resolución biministerial sobre la ministerial (L. 3351, feb. 21/2006, art. $8^{\circ}$. Par. I). Desde luego, en sus relaciones mutuas las resoluciones emanadas de los órganos ejecutivos descentralizados y autónomos, y las emanadas del órgano central, se rigen por la competencia material de sus respectivos órganos productores.

47 En el sentido argumentado, la redacción del artículo 172.8 es técnicamente suficiente. 


\section{CONCLUSIÓN: EL ARTÍCULO 410. II RECONSTRUIDO}

Dadas las relaciones entre sus fuentes, son los criterios de jerarquía y de competencia los que determinan la estructura del sistema jurídico boliviano (sistema nacional). Según el criterio de competencia, a partir de su tercer nivel jerárquico el sistema está organizado en subsistemas normativos. Uno de ellos es el subsistema central; los demás, los distintos subsistemas descentralizados y autónomos, incluyendo los subsistemas indígenas originarios campesinos. Dichos subsistemas están en pie de igualdad; sus normas no se derogan recíprocamente, desde que se estructuran según la competencia material de sus distintos órganos productores. Así, la estructura del sistema es la siguiente:

1. En el sistema nacional la supremacía jerárquica corresponde a la Constitución, según resulte interpretada por el Tribunal Constitucional Plurinacional (preeminencia sobre el derecho ordinario y carácter vinculante de los precedentes constitucionales). Por Constitución se entiende su texto formal, los tratados sobre derechos humanos ratificados por el país y las normas de derecho comunitario (también ratificadas si su naturaleza es convencional o incorporadas según lo establezcan las normas originarias tratándose de derecho comunitario derivado).

2. Siguiendo con el sistema nacional, subordinadas directamente a la Constitución están: a) las leyes aprobadas por dos tercios (las leyes expresas que levanten la prohibición de asentamiento de extranjeros en la zona de seguridad fronteriza y la Ley Marco de Autonomías y Descentralización); y b) los tratados sobre cuestiones limítrofes y aquellos de cualquier materia (menos los que corresponden al bloque de constitucionalidad) que eventualmente hayan sido aprobados por referendo popular, si es que se toma la primera interpretación propuesta (rango supralegal para los tratados aprobados por referendo popular vinculante).

3. En un tercer nivel nacional, también subordinadas directamente a la Constitución por razón de la competencia material de sus respectivos órganos productores, estarían: a) las leyes ordinarias, subordinadas además a las leyes aprobadas por dos tercios; b) los estatutos autonómicos y las cartas orgánicas, subordinados también a la Ley Marco, pero no a las leyes expresas; y c) los tratados, si es que se toma la segunda interpretación propuesta (rango de ley, pero mayor fuerza jurídica pasiva).

4. A partir del tercer nivel nacional, la estructura del sistema se define sólo en términos de competencia. Comenzando con los subsistemas normativos descentralizados y autónomos, su estructura es la siguiente: a) la supremacía en cada subsistema la ostentan los respectivos estatutos autonómicos y cartas orgánicas, que pertenecen al tercer nivel del sistema nacional; b) subordinadas a los estatutos o cartas, según corresponda, están las normas de los órganos legislativos de cada subsistema; y c) subordinadas a las normas de sus órganos 
legislativos están las de normas de sus respectivos órganos ejecutivos, salvo cuando éstos ejerzan competencias normativas derivadas directamente de la norma suprema de sus subsistemas. También son subsistemas normativos autónomos los subsistemas indígenas originarios campesinos, en los cuales se aplica su derecho consuetudinario en las materias reconocidas en sus respectivos estatutos indígenas, en ejecución de la distribución de competencias entre los distintos subsistemas normativos efectuada por la Constitución.

5. Por último, también subordinadas al tercer nivel del sistema nacional, en el subsistema central siguen las normas del órgano ejecutivo (decretos y resoluciones supremas), que tienen las leyes como fuente de validez, salvo que se trate del ejercicio de atribuciones constitucionales directas, en cuyo caso se subordinan sólo a la Constitución; y de ahí, en los subsiguientes niveles, siguen las demás normas producidas por las distintas reparticiones del órgano ejecutivo central, según la ordenación jerárquica establecida por sus normas de fuente legal. 


\section{BIBLIOGRAFÍA}

Horacio Andaluz. El derecho internacional en el sistema de fuentes: propuesta de artículos para la nueva Constitución de Bolivia. Revista Boliviana de Derecho. 6. (2008).

Horacio Andaluz. Positivismo normativo y derecho internacional. $1^{\text {a }}$ edición. La Paz. Plural. (2005).

Jorge Asbun. Estudios constitucionales. 1ª edición. Santa Cruz. El País. (2008).

Jean Bodin. Los seis libros de la república. $1^{\text {a }}$ edición. Madrid. Centro de Estudios Constitucionales. (1992).

Raymond Carré de Malberg. Teoría general del Estado (reimpresión). México D.F. Fondo de Cultura Económica. (2000).

Arthur L. Goodhart. Determining the ratio decidendi of a case. (40 Yale Law Journal, 1930).

H.L.A. Hart. The concept of law. $2^{\mathrm{a}}$ edición. Nueva York. Oxford University Press. (1994).

Thомаs HobBes. Leviathan. $1^{\text {a }}$ edición. Nueva York. Penguin. (1968).

Hans Kelsen. Introduction to the problems of legal theory. $1^{\mathrm{a}}$ reimpresión. Nueva York. Clarendon Press. (2002). (1995).

Teoría general del derecho y del Estado. $5^{\text {a }}$ reimpresión. México D.F. UNAM.

Karl Llewellyn. The Bramble Bush (reimpresión). Nueva York. Oceana/Oxford University Press. (1961).

John Henry Merryman. La tradición jurídica romano-canónica. $8^{a}$ reimpresión. México D.F. Fondo de Cultura Económica. (2003).

JoSEPH RAz. The concept of a legal system. $2^{\mathrm{a}}$ edición. Nueva York. Oxford University Press. (1980). Press. (2002).

Practical reason and norms (reimpresión). Nueva York. Oxford University

Jürgen SCHwABE. Cincuenta años de jurisprudencia del Tribunal Constitucional Federal alemán. $1^{a}$ edición. Montevideo. Fundación Konrad Adenauer. (2003).

Robert Walter. Problemas centrales de la teoría pura del derecho. $1^{\text {a }}$ edición. Bogotá. Universidad Externado de Colombia. (2001). 